\title{
Electron Capture in Charge-Tagged Peptides. Evidence for the Role of Excited Electronic States
}

\author{
Julia Chamot-Rooke, ${ }^{\text {a }}$ Christian Malosse, ${ }^{\text {a Gilles Frison, }}{ }^{\text {a }}$ \\ and František Tureček ${ }^{\mathrm{b}}$ \\ ${ }^{a}$ Laboratoire des Mécanismes Réactionnels, Department of Chemistry, Ecole Polytechnique, CNRS, Palaiseau, \\ France \\ ${ }^{\mathrm{b}}$ Department of Chemistry, University of Washington, Seattle, Washington, USA
}

\begin{abstract}
Electron capture dissociation (ECD) was studied with doubly charged dipeptide ions that were tagged with fixed-charge tris-(2,4,6-trimethoxyphenyl)phosphonium-methylenecarboxamido (TMPP-ac) groups. Dipeptides GK, KG, AK, KA, and GR were each selectively tagged with one TMPP-ac group at the N-terminal amino group while the other charge was introduced by protonation at the lysine or arginine side-chain groups to give (TMPP-ac-peptide $+\mathrm{H})^{2+}$ ions by electrospray ionization. Doubly tagged peptide derivatives were also prepared from GK, $\mathrm{KG}, \mathrm{AK}$, and $\mathrm{KA}$ in which the fixed-charge TMPP-ac groups were attached to the $\mathrm{N}$-terminal and lysine side-chain amino groups to give (TMPP-ac-peptide-ac-TMPP) ${ }^{2+}$ dications by electrospray. ECD of (TMPP-ac-peptide $+\mathrm{H})^{2+}$ resulted in $72 \%$ to $84 \%$ conversion to singly charged dissociation products while no intact charge-reduced (TMPP-ac-dipeptide $+\mathrm{H})^{+\bullet}$ ions were detected. The dissociations involved loss of $\mathrm{H}$, formation of (TMPP $+\mathrm{H})^{+}$, and $\mathrm{N}-\mathrm{C}_{\alpha}$ bond cleavages giving TMPP- $\mathrm{CH}_{2} \mathrm{CONH}_{2}{ }^{+}\left(c_{0}\right)$ and $c_{1}$ fragments. In contrast, ECD of (TMPP-ac-peptide-ac-TMPP) ${ }^{2+}$ resulted in $31 \%$ to $40 \%$ conversion to dissociation products due to loss of neutral TMPP molecules and 2,4,6-trimethoxyphenyl radicals. No peptide backbone cleavages were observed for the doubly tagged peptide ions. Ab initio and density functional theory calculations for $\left(\mathrm{Ph}_{3} \mathrm{P}-\mathrm{ac}-\mathrm{GK}+\mathrm{H}\right)^{2+}$ and $\left(\mathrm{H}_{3} \mathrm{P}-\mathrm{ac}-\mathrm{GK}+\mathrm{H}\right)^{2+}$ analogs indicated that the doubly charged ions contained the lysine side-chain $\mathrm{NH}_{3}{ }^{+}$group internally solvated by the $\mathrm{COOH}$ group. The distance between the charge-carrying phosphonium and ammonium atoms was calculated to be 13.1-13.2 $\AA$ in the most stable dication conformers. The intrinsic recombination energies of the $\mathrm{TMPP}^{+}$-ac and $(\mathrm{GK}+\mathrm{H})^{+}$moieties, 2.7 and $3.15 \mathrm{eV}$, respectively, indicated that upon electron capture the ground electronic states of the (TMPPac-peptide $+\mathrm{H})^{+} \cdot$ ions retained the charge in the TMPP group. Ground electronic state (TMPP-ac-GK $+\mathrm{H})^{+}$ions were calculated to spontaneously isomerize by lysine $\mathrm{H}$-atom transfer to the $\mathrm{COOH}$ group to form dihydroxycarbinyl radical intermediates with the retention of the charged TMPP group. These can trigger cleavages of the adjacent $\mathrm{N}-\mathrm{C}_{\alpha}$ bonds to give rise to the $c_{1}$ fragment ions. However, the calculated transition-state energies for GK and GGK models suggested that the ground-state potential energy surface was not favorable for the formation of the abundant $c_{0}$ fragment ions. This pointed to the involvement of excited electronic states according to the Utah-Washington mechanism of ECD. (J Am Soc Mass Spectrom 2007, 18, 2146-2161) (C 2007 American Society for Mass Spectrometry
\end{abstract}

$\mathrm{E}$ lectron-based methods of gas-phase ion chemistry rely on partial or complete neutralization of gas-phase ions to produce transient species with open electronic shells that undergo various dissociations [1]. Amongst the several electron-based methods in current use, electron capture dissociation (ECD) [2] has received much attention lately because of its potential for peptide and protein analysis [3]. ECD relies on dissociative recombination [4] with low-energy electrons of multiply charged, closed-shell ions that are

Address reprint requests to Dr. F. Tureček, Department of Chemistry, University of Washington, Bagley Hall, Box 351700, Seattle, WA 9181951700, USA. E-mail: turecek@chem.washington.edu trapped in an ion-cyclotron resonance cell, followed by mass spectrometric analysis of the charged dissociation products. In parallel with the analytical applications of ECD [5], there has been much interest in studying the dissociation mechanisms of cation-radicals produced by ion-electron recombination [6]. Experimental studies relied on peptide models in which the nature and sequence of amino acid residues were varied and the structure effects on ECD were interpreted on the basis of fragment ion analysis [6]. Computational studies of amide and small peptide models have addressed the electronic properties, dissociation, and transition-state energies of open-shell intermediates that were suggested to play a role in ECD [7-10]. The crucial question 


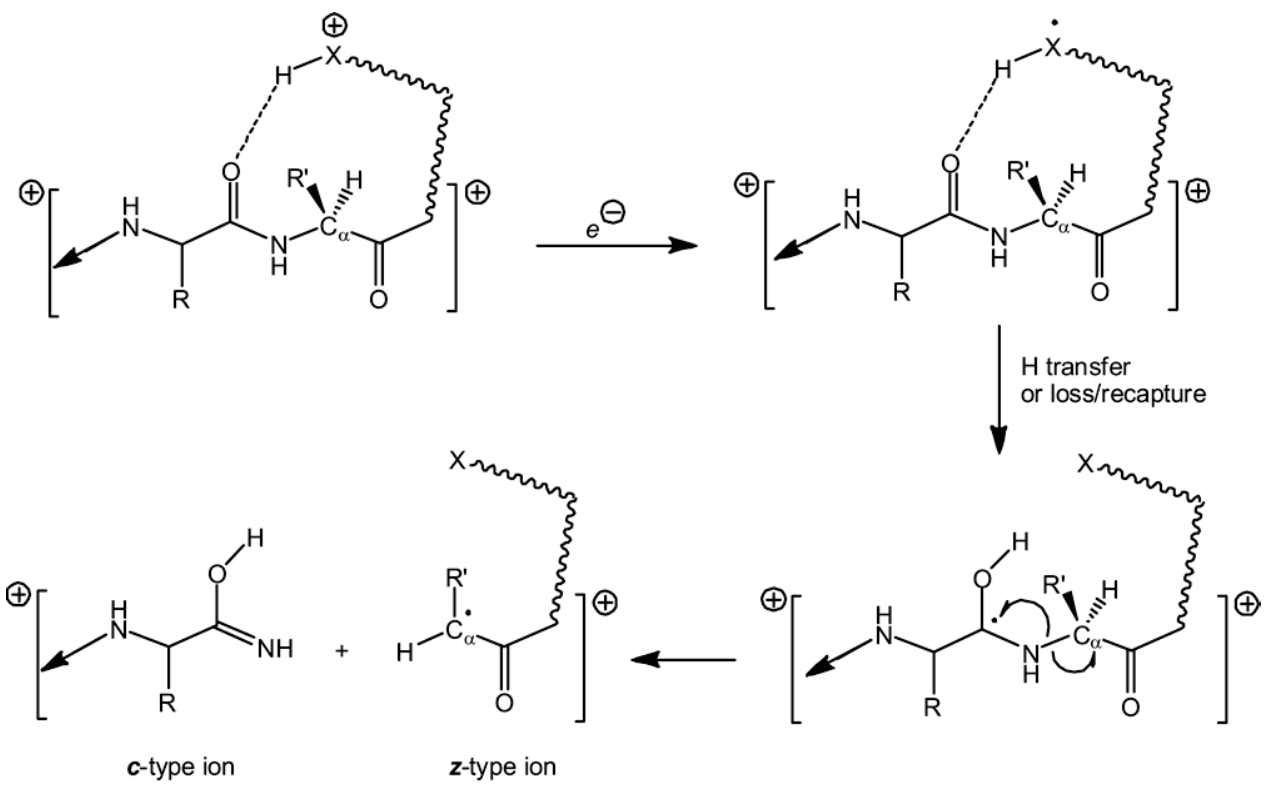

Scheme 1

in ECD concerns the site of electron attachment in the peptide ion that is thought to trigger bond dissociations. A possible electron attachment site is one of the charge-carrying groups, which in peptides are the protonated lysine, arginine, or histidine side-chain groups, the N-terminal amino group, or an amide group. Electron attachment in a protonated side-chain group $\boldsymbol{X}$, Scheme 1) produces a radical that may either dissociate or interact with the peptide backbone to transfer a hydrogen atom to the amide carbonyl through protoncoupled electron-transfer [8]. Such a rearrangement would produce an aminoketyl radical intermediate, which can be expected to readily undergo a $\beta$-fission dissociation [9]. Quantum theory calculations indicated that of several possible $\beta$-fission processes, $\mathrm{N}-\mathrm{C}_{\alpha}$ bond cleavages had the lowest activation energies $[9,10]$, in keeping with the fact that $\mathrm{N}-\mathrm{C}_{\alpha}$ bond cleavages are regularly observed in ECD of peptide cations.

This so-called Cornell mechanism of ECD [11] has been scrutinized by studying the effects of electron attachment to basic side-chain groups in selected model systems, e.g., arginine amide [11], histidine N-methylamide [12], and $\beta$-alanine-N-methylamide [13], which had unequivocal protonation sites and well-defined conformations of gas-phase ions. The tendency for proton-coupled electrontransfer to the amide groups decreases from ammonium (as in lysine and $\beta$-alanine) through imidazolium (as in histidine) to guanidinium (as in arginine), which appears to be a poor hydrogen atom donor [11].

Another mechanism of ECD, called the Utah-Washington (UW) model [11], has been put forth to explain frequent dissociations of $\mathrm{N}-\mathrm{C}_{\alpha}$ bonds that for steric reasons may not be able to receive a hydrogen atom from the protonation sites of the precursor ions in their initial conformation(s) [14, 15]. The UW model (Scheme 2) presumes competitive electron capture in amide $\pi^{*}$ orbitals, which are stabilized by electrostatic interaction with the remote charge-carrying groups. Electron capture dramatically changes the electronic properties of the amide group by substantially increasing its basicity (hence the amide superbase model) [14], while also lowering the $\mathrm{N}-\mathrm{C}_{\alpha}$ bond activation [14,15] and dissociation energy compared with the same properties of a neutral amide group. Upon electron capture, the Coulomb repulsion between the positively charged groups is compensated by attraction between the electron-carrying amide group and the remaining charge sites and, thus, the charge-reduced intermediate can undergo conformational change followed by exothermic proton transfer (path $a$ ) to form an aminoketyl intermediate that dissociates by $\mathrm{N}-\mathrm{C}_{\alpha}$ bond cleavage forming a $c \ldots z^{+\bullet}$ fragment pair. Alternatively, the dissociation can follow path $b$ in which the $\mathrm{N}-\mathrm{C}_{\alpha}$ bond cleavage and proton transfer steps are reversed. Note that the enol-imidate intermediate from $\mathrm{N}-\mathrm{C}_{\alpha}$ bond cleavage in path $\boldsymbol{b}$ is also highly basic and so we call it imine superbase in Scheme 2.

Distinction of the Cornell model on one hand and the alternative UW models on the other poses challenges in both experimental and computational approaches. On the experimental side, it is often difficult to control both the charge sites and ion conformations in gas-phase ions to provide well-defined reactant structures for reactivity studies. On the computational side, the multiply charged peptides used in ECD experiments are usually too big to allow for good quality quantum theory calculations that would adequately represent the rather unusual electronic properties of peptide cationradicals [8-14].

In the present work, we attempt to bridge this gap between experiment and theory by studying ECD of doubly charged dipeptide ions that were furnished with a 


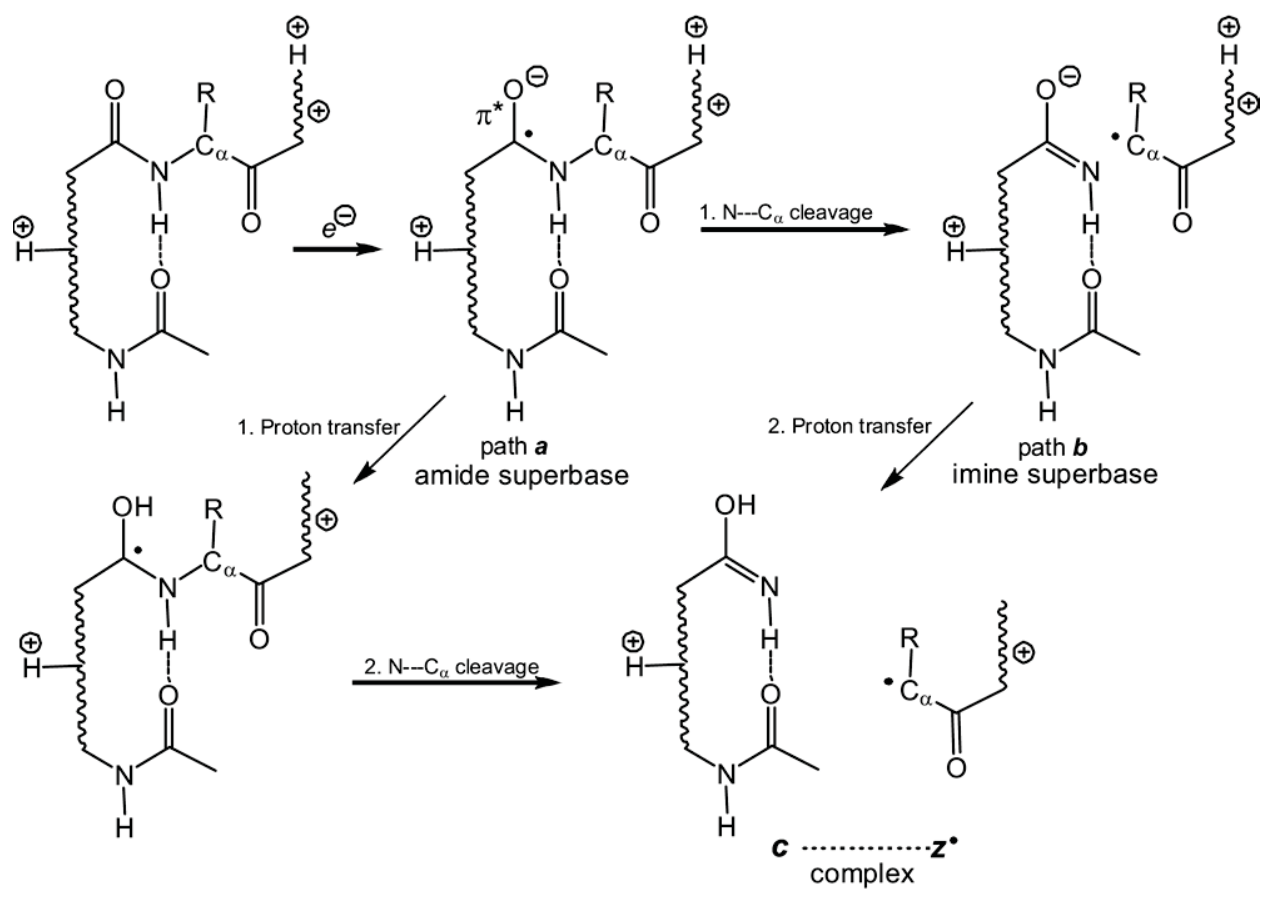

Scheme 2

permanent charge at a fixed known position. As a chargecarrying group we chose tris-(2,4,6-trimethoxyphenyl)phosphonium (TMPP) that can be selectively attached to amino groups at the peptide N-terminus or in the lysine side-chain via a methylenecarboxamide linker [16]. Analogous TMPP derivatives have been used to introduce a fixed charge in larger peptides for ion dissociation [17] and ECD studies [18]. The other charge needed for ECD is introduced as a proton by electrospray ionization. The proton position is determined by the presence in the peptide of a single basic group, e.g., the lysine $\varepsilon$-amine, as in $\mathrm{GK}, \mathrm{KG}, \mathrm{AK}$, and $\mathrm{KA}$, or the arginine guanidine group as in GR. A potential advantage of these small dipeptide models is that the doubly charged gas-phase ions assume well-defined conformations due to Coulomb repulsion between the positive charges, which represents the dominant intramolecular interaction, and moreover, the gasphase ion structures can be ascertained by quantum theory calculations. We also report ECD experiments with the same dipeptides containing two permanently charged TMPP groups. These derivatives do not possess mobile protons in the charged groups that would be needed to cause dissociations according to the Cornell model. We note that fixed-charge labeled peptides have also been used recently for studies of electron-transfer dissociation [19].

\section{Experimental}

\section{Materials}

The peptides (Gly-Lys, Lys-Gly, Ala-Lys, Lys-Ala, and Gly-Arg) were obtained from Sigma-Aldrich (SaintQuentin Fallavier, France) and used without purifica- tion. Mono-TMPP derivatives were prepared by mixing a peptide solution ( $1 \mathrm{nmol}$ of peptide in $2 \mu \mathrm{L}$ acetonitrile/water (2/8) (vol/vol) and $2 \mu \mathrm{L}$ of $50 \mathrm{mM}$ ammonium bicarbonate buffer ( $\mathrm{pH} 8)$ ) with $1 \mu \mathrm{L}$ of $10 \mathrm{mM}$ (N-succinimidyloxycarbonyl-methyl)-tris(2,4,6-trimethoxyphenyl)phosphonium bromide (Sigma-Aldrich). Under these conditions the more basic lysine amino group is protected by protonation and does not react. To introduce two TMPP groups, ammonium bicarbonate were replaced by $2 \mu \mathrm{L}$ of $0.8-\mathrm{M} \mathrm{N}, \mathrm{N}$-diethylmethylamine that deprotonated the lysine ammonium group and rendered it reactive to the TMPP active ester reagent. The final solution was vortexed for $30 \mathrm{~s}$ and then sonicated in a water bath for $30 \mathrm{~min}$ (final bath temperature $<30^{\circ} \mathrm{C}$ ). The resulting mixture was evaporated (centrifugal evaporator) to dryness and the derivatives were stored at $-20^{\circ} \mathrm{C}$. Peptide solutions in acetonitrile/water/formic acid (49.5/49.5/1) at 2 to 20 $\mu \mathrm{M}$ concentrations were used for direct infusion using the electrospray ion source for the FT-ICR instrument and nanoelectrospray ion source for the QTOF mass spectrometer.

\section{Methods}

Electron capture dissociation mass spectra were obtained on a 7-T APEX III FT-ICR mass spectrometer (Bruker Daltonik, Bremen, Germany). Positive ions were produced by direct infusion of the peptide solutions into an external Apollo electrospray ion source (Bruker Daltonik) at a flow rate of $1.5 \mu \mathrm{L} / \mathrm{min}$ with the assistance of $\mathrm{N}_{2}$ nebulizing gas. The ESI source parameters were: cylinder, $0 \mathrm{~V}$; capillary, $-4000 \mathrm{~V}$; end plate, 
-3800 V, cap exit, $50 \mathrm{~V}$; skimmer 1, $16.4 \mathrm{~V}$; skimmer 2, $7.1 \mathrm{~V}$; offset, $0.3 \mathrm{~V}$; trap and extract, $15 \mathrm{~V}$ and $-10 \mathrm{~V}$, respectively; drying temperature, $140^{\circ} \mathrm{C}$. Ions were stored in the source region in a hexapole guide for $2 \mathrm{~s}$ and pulsed into the detection cell through a series of electrostatic lenses. Ions were finally trapped in the cell using gas-assisted dynamic trapping (Xe pulses, upper pressure around $10^{-7} \mathrm{mbar}$ ) with front and back trapping voltages of 3.0 and $3.5 \mathrm{~V}$ for trapping, reduced to 0.9 and $0.95 \mathrm{~V}$ for detection. Ions of interest were isolated by radio frequency (rf) ejection of all unwanted ions using both low-voltage single rf pulses (soft shots) at their resonance frequencies and a chirp excitation covering the region of interest. ECD experiments were performed with an indirectly heated cathode operated at $1.9 \mathrm{~A}$ of heater current. Isolated doubly charged ions were irradiated during $300 \mathrm{~ms}$ with electrons having $<1$ eV kinetic energy. Mass spectra were acquired from $\mathrm{m} / \mathrm{z}$ 200 to 2000 with $256 \mathrm{k}$ data points and monoisotopic peaks were automatically labeled using the XMASS 6.1.4 (Bruker Daltonics) software.

Collision-induced dissociation (CID) mass spectra were obtained on a Q-TOF Premier (Waters Corp., Milford, MA). The Q-TOF Premier is a quadrupole, orthogonal acceleration time-of-flight tandem mass spectrometer. Nanoelectrospray ionization in positive mode (ZSpray) was used. Nano-electrospray glass capillaries (Proxeon, Odense, Denmark) were filled with $2 \mu \mathrm{L}$ of the peptide solution and subsequently opened by breaking the tapered end of the tip under a microscope. The source temperature was set to $80{ }^{\circ} \mathrm{C}$. The capillary and cone voltages were set to 3000 and $40 \mathrm{~V}$, respectively. The precursor ion selected in the first quadrupole was collisionally activated with argon using variable collision energy ( 10 to $45 \mathrm{eV}$ for singly charged precursors and 5 to $20 \mathrm{eV}$ for doubly charged parent ions). The TOF data were collected between $\mathrm{m} / \mathrm{z} 100$ to 1000 . Scans were collected for $1 \mathrm{~s}$ and accumulated to increase the signal/noise ratio. Mass Lynx 4.1 was used both for acquisition and data processing. An external calibration in MS was done with clusters of phosphoric acid (0.01 M in 50:50 acetonitrile: $\mathrm{H}_{2} \mathrm{O}$, vol:vol) before the analysis. The mass range for the calibration was $m / z 70$ to 2000 .

\section{Calculations}

Standard ab initio calculations were performed using the Gaussian 03 suite of programs [20]. Optimized geometries were obtained by density functional theory calculations using Becke's hybrid functional (B3LYP) [21] and the $6-31+G(d, p)$ basis set for dications and reoptimized with $6-31++G(d, p)$ for cation-radicals. The use of the $6-31++G(d, p)$ basis set was motivated by the need to incorporate diffuse functions on $\mathrm{C}, \mathrm{N}, \mathrm{O}, \mathrm{P}$, and $\mathrm{H}$ in calculations of hypervalent ammonium and phosphonium radicals and transition states for their dissociations and isomerizations. Hypervalent radicals have unpaired electrons in frontier molecular orbitals that resemble atomic Rydberg orbitals, 3s and 3p for $\mathrm{N}$ and 3d, 4s, $4 \mathrm{p}$ for
P, which show substantial diffuse character, as studied previously for simple systems [22]. The optimized structures are shown in the pertinent schemes and figures. Complete optimized structures of all local minima and transition states can be obtained from the corresponding author upon request. Spin unrestricted calculations were performed for all open-shell systems. Stationary points were characterized by harmonic frequency calculations with B3LYP/6-31+G(d,p) as local minima (all real frequencies) and first-order saddle points (one imaginary frequency). The calculated frequencies were scaled with 0.963 [23] and used to obtain zero-point energy corrections, enthalpies, and entropies. The rigid-rotor-harmonic-oscillator (RRHO) model was used in thermochemical calculations except for low-frequency modes where the vibrational enthalpy terms that exceeded 0.5 RT were replaced by free internal rotation terms equal to $0.5 \mathrm{RT}$.

Improved energies were obtained by single-point calculations using B3LYP and Møller-Plesset perturbation theory (MP2-frozen core) [24] that were carried out at several levels of theory, including the $6-311++G(2 d, p)$ split-valence triple- $\zeta$ basis set furnished with polarization and diffuse functions. For the molecular systems studied here, the larger basis set comprised 648 to 1005 basis functions (968 to 1529 primitive gaussians). The spin unrestricted formalism was used for calculations of open-shell systems. Contamination by higher spin states was modest, as judged from the expectation values of the spin operator $\left\langle S^{2}\right\rangle$ that were $\leq 0.76$ for UB3LYP and $\leq 0.78$ for UMP2 calculations. The UMP2 energies were corrected by spin annihilation [25] that reduced the $\left(S^{2}\right)$ to close to the theoretical value for a pure doublet state (0.75) after spin projection (PMP2). The B3LYP and MP2 energies calculated with the larger basis set were combined according to the B3-MP2 scheme, as described previously [26]. The largest molecular systems exceeded our computational resources for performing MP2 calculations, and for those only the B3LYP data are reported.

The performance of the B3-PMP2 scheme was checked by benchmark single-point calculations with coupledcluster theory [27] including single, double, and disconnected triple excitations $(\operatorname{CCSD}\{T\})$ [28] that were performed with the large correlation-consistent basis set of triple- $\zeta$ quality furnished with diffuse functions on all atoms, aug-cc-pVTZ [29]. The calculated recombination energies for $\mathrm{PH}_{4}^{+}$(eq 1) and dissociation energies for $\mathrm{PH}_{4}{ }^{-}$(eq 2) indicated that the B3-PMP2 scheme can be reliably used for phosphonium ions and radicals.

$$
\begin{aligned}
& \mathrm{PH}_{4}^{+}+\mathrm{e} \rightarrow \mathrm{PH}_{4}^{\cdot} \\
& \mathrm{RE}_{\text {adiab }}=-5.70 \mathrm{eV}(\mathrm{B} 3-\mathrm{PMP} 2 / 6-311++\mathrm{G}(2 \mathrm{~d}, \mathrm{p}) \\
& \quad / / \mathrm{B} 3 \mathrm{LYP} / 6-311++\mathrm{G}(2 \mathrm{~d}, \mathrm{p})) \\
& \mathrm{RE}_{\text {adiab }}=-5.70 \mathrm{eV}(\mathrm{CCSD}(\mathrm{T}) / \text { aug-cc-pVTZ } \\
& \quad / / \mathrm{B} 3 \mathrm{LYP} / 6-311++\mathrm{G}(2 \mathrm{~d}, \mathrm{p}))
\end{aligned}
$$


Table 1. ECD spectra of (TMPP-ac-peptide $+\mathrm{H})^{2+}$ ions

\begin{tabular}{|c|c|c|c|c|c|}
\hline \multirow[b]{2}{*}{$\operatorname{lon}^{a}$} & \multicolumn{5}{|c|}{ Peptide } \\
\hline & GK & KG & AK & KA & GR \\
\hline$(\text { TMPP-ac-peptide }+\mathrm{H})^{2+}$ & $\begin{array}{c}1^{2+} \\
388.6618 \\
388.6619^{a}\end{array}$ & $\begin{array}{c}2^{2+} \\
388.6618\end{array}$ & $\begin{array}{c}\mathbf{3}^{2+} \\
395.6696 \\
395.6697\end{array}$ & $\begin{array}{c}4^{2+} \\
395.6695\end{array}$ & $\begin{array}{c}\mathbf{5}^{2+} \\
402.6648 \\
402.665\end{array}$ \\
\hline$(\text { TMPP-ac-peptide }+\mathrm{H})^{+\bullet}$ & - & - & - & - & - \\
\hline$(\text { TMPP-ac-peptide) })^{+}$ & $\begin{array}{l}776.3153 \\
776.3159\end{array}$ & 776.3153 & $\begin{array}{l}790.3313 \\
790.3316\end{array}$ & 790.3249 & $\begin{array}{l}804.3211 \\
804.322\end{array}$ \\
\hline$(\text { TMPP-ac-peptide) })^{+}-\mathrm{CH}_{2} \mathrm{O}$ & - & $\begin{array}{l}746.3065 \\
746.3053\end{array}$ & - & $\begin{array}{l}760.3086 \\
760.3181\end{array}$ & - \\
\hline$c_{1}$ & $\begin{array}{l}647.2368 \\
647.2479\end{array}$ & $\begin{array}{l}718.3099 \\
718.3105\end{array}$ & $\begin{array}{l}661.2531 \\
661.2548\end{array}$ & $\begin{array}{l}718.3116 \\
718.3105\end{array}$ & $\begin{array}{l}647.2372 \\
647.237\end{array}$ \\
\hline Loss of $\mathrm{C}_{9} \mathrm{H}_{11} \mathrm{O}_{3}$ & - & - & - & - & $\begin{array}{l}638.2598 \\
638.259\end{array}$ \\
\hline $\boldsymbol{c}_{1}-\mathrm{NH}_{3}$ & - & - & - & $\begin{array}{l}701.2868 \\
701.2839\end{array}$ & - \\
\hline TMPP-ac- $\mathrm{NH}_{2}\left(\boldsymbol{c}_{0}\right)$ & $\begin{array}{l}590.2154 \\
590.2197\end{array}$ & 590.2157 & 590.2156 & 590.2169 & 590.2164 \\
\hline TMPP-NH$H_{2}-\mathrm{NH}_{3}$ & - & - & - & $\begin{array}{l}573.1905 \\
573.1963\end{array}$ & - \\
\hline $\mathrm{Ar}_{3} \mathrm{PH}^{\mathrm{b}}$ & $\begin{array}{l}533.1947 \\
533.1941\end{array}$ & 533.1946 & 533.1943 & 533.1947 & 533.1946 \\
\hline $\mathrm{Ar}_{3} \mathrm{PH}^{+}-\mathrm{CH}_{3} \mathrm{OH}$ & $\begin{array}{l}501.1693 \\
501.1678\end{array}$ & - & 501.1680 & - & - \\
\hline
\end{tabular}

${ }^{a}$ All spectra have been internally calibrated using the accurate $m / z$ values of the parent ion, $(\mathrm{M}-\mathrm{Ar})^{+}$, and $\left(\mathrm{M}-\mathrm{Ar}_{3} \mathrm{P}\right)^{+}$fragment ions. Calculated $m / z$ values in italics.

${ }^{\mathrm{b}} \mathrm{Ar}=2,4,6$-trimethoxyphenyl.

$$
\begin{aligned}
& \mathrm{PH}_{4}^{\circ} \rightarrow \mathrm{PH}_{3}+\mathrm{H}^{\bullet} \\
& \Delta H_{y, 0}^{\circ}=16.9 \mathrm{~kJ} \mathrm{~mol}^{-1}(\mathrm{~B} 3-\mathrm{PMP} 2 / 6-311 \\
& \left.\quad++\mathrm{G}(2 \mathrm{~d}, \mathrm{p}) / / \mathrm{B} 3 L Y P_{6} 6-311+\mathrm{G}(2 \mathrm{~d} / \mathrm{p})\right) \\
& \Delta H_{g, 0}^{\circ}=14.9 \mathrm{~kJ} \mathrm{~mol}{ }^{-1}(\mathrm{CCSD}(\mathrm{T}) / \text { aug-cc-pVTZ } \\
& \quad / / \mathrm{B} 3 \mathrm{LYP} / 6-311++\mathrm{G}(2 \mathrm{~d}, \mathrm{p}))
\end{aligned}
$$

Excited-state energies were calculated with timedependent density functional theory [30] using the B3LYP functional and the $6-311++G(2 d, p)$ basis set. Natural Population Analysis (NPA) [31] was used to calculated atomic charges and spin densities with B3LYP/ $6-31++G(2 d, p)$. Rice-Ramsperger-Kassel-Marcus (RRKM) theory was used to calculate unimolecular rate constants, as reported previously [13].

\section{Results}

\section{ECD Spectra}

Electron capture dissociations were studied with dications derived from singly TMPP-derivatized dipeptides that upon electrospray gave (TMPP-ac-peptide $+\mathrm{H})^{2+}$ ions containing one fixed triarylphosphonium charge and one protonation site. These ions are denoted as $\mathbf{1}^{2+}$, $2^{2+}, 3^{2+}, 4^{2+}$, and $5^{2+}$ for GK, KG, AK, KA, and GR, respectively. Dications derived from doubly-derivatized peptides gave (TMPP-ac-peptide-ac-TMPP) ${ }^{2+}$ ions containing two fixed-charge triarylphosphonium groups which are denoted as $6^{2+}, 7^{2+}, 8^{2+}$, and $9^{2+}$ for GK, KG,
$\mathrm{AK}$, and KA, respectively. The "ac" stands for the $-\mathrm{CH}_{2} \mathrm{CO}$ - group linking the $\mathrm{Ar}_{3} \mathrm{P}$ phosphonium group to the peptide amino group, according to the notation used by Watson et al. [16]. The peptide fragment ions are denoted by the standard letter symbols $\left(a_{1}, c_{1}, c_{0}\right.$, etc.) [32] where index 1 stands for cleavage between the amino acid residues and index 0 stands for bond cleavages at the TMPP linker amide group.

ECD of all peptide derivatives resulted in complete dissociation of the charge-reduced ions, and no cationradicals corresponding to (TMPP-ac-peptide $+\mathrm{H})^{+\bullet}$ or (TMPP-ac-peptide-ac-TMPP) $^{+}{ }^{-}$were detected. ECD of the (TMPP-ac-peptide $+\mathrm{H})^{2+}$ dications showed substantial conversions to singly charged dissociation products, as defined by the formula: \%conversion = $100 \Sigma I_{\mathrm{ECD}} /\left(\Sigma I_{\mathrm{ECD}}+I_{\text {precursor }}\right)$, which ranged within $79 \%$ to $84 \%$ for GK, KG, AK, and KA, and $72 \%$ for GR. The conversions in the (TMPP-ac-peptide-ac-TMPP) ${ }^{2+}$ group were $31 \%$ to $40 \%$ or about half of those for the singly derivatized peptide dications.

The fragments formed from the (TMPP-ac-peptide + $\mathrm{H})^{+\cdot}$ intermediates were identified on the basis of accurate mass measurements and homologous mass shifts between Ala and Gly (Table 1). The ECD spectra are represented by those of (TMPP-ac-GK $+\mathrm{H})^{2+}\left(\mathbf{1}^{2+}\right)$ and (TMPP-ac-KG $+\mathrm{H})^{2+}\left(2^{2+}\right)$ (Figure $\left.1 \mathrm{a}, \mathrm{b}\right)$. ECD of $\mathbf{1}^{2+}$ produced ions at $\mathrm{m} / \mathrm{z} 776$ (loss of $\mathrm{H}$ ), 746 (loss of $\mathrm{H}$ and $\left.\mathrm{CH}_{2} \mathrm{O}\right), 647 c_{1}$ fragment, loss of $\left.\mathrm{C}_{6} \mathrm{H}_{12} \mathrm{NO}_{2}\right), 590 c_{0}$ fragment, $\left.\mathrm{Ar}_{3} \mathrm{P}^{+} \mathrm{CH}_{2} \mathrm{CONH}_{2}\right), 533\left(\mathrm{Ar}_{3} \mathrm{PH}^{+}\right)$, and 501 $\left(\mathrm{Ar}_{3} \mathrm{PH}-\mathrm{CH}_{3} \mathrm{OH}\right)^{+}$. ECD of $(\mathrm{TMPP}-\mathrm{ac}-\mathrm{AK}+\mathrm{H})^{2+}$ 


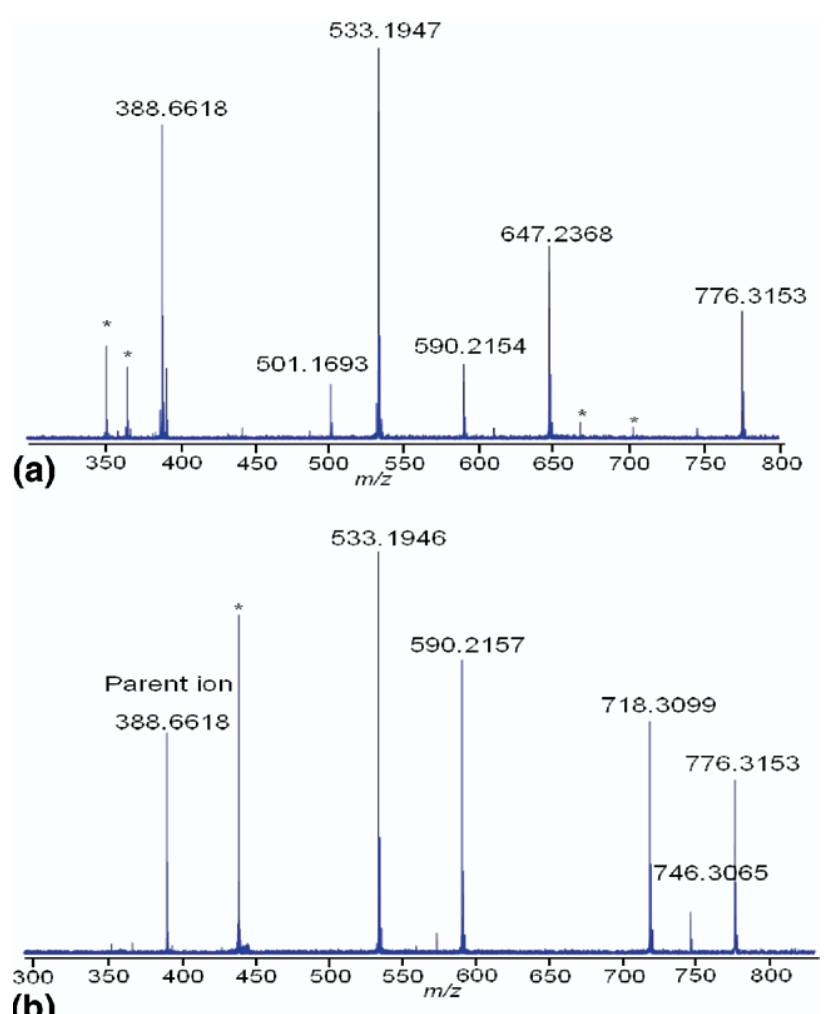

(b)

Figure 1. Electron-capture dissociation mass spectra of (a) $(\mathrm{TMPP}-\mathrm{ac}-\mathrm{GK}+\mathrm{H})^{2+}\left(\mathbf{1}^{2+}\right)$ and $(\mathbf{b})(\mathrm{TMPP}-\mathrm{ac}-\mathrm{KG}+\mathrm{H})^{2+}\left(\mathbf{2}^{2+}\right)$ precursor ions at $m / z$ 388.6618. Noise peaks are marked with asterisks.

$\left(3^{2+}\right)$ gave analogous and homologous fragments of the same type (Table 1). ECD of $\mathbf{2}^{2+}$ produced ions at $\mathrm{m} / \mathrm{z} 776$ (loss of $\mathrm{H}$ ), 746 (loss of $\mathrm{H}$ and $\mathrm{CH}_{2} \mathrm{O}$ ), $718 c_{1}$ fragment, loss of $\left.\mathrm{C}_{3} \mathrm{H}_{5} \mathrm{O}_{2}\right), 590 c_{0}$ fragment, $\left.\mathrm{Ar}_{3} \mathrm{P}^{+} \mathrm{CH}_{2} \mathrm{CONH}_{2}\right), 573\left(c_{0}-\mathrm{NH}_{3}\right)$, and $533\left(\mathrm{Ar}_{3} \mathrm{PH}^{+}\right)$. ECD of (TMPP-ac-KA $+\mathrm{H})^{2+}\left(4^{2+}\right)$ gave analogous and homologous fragment ions of the same type (Table 1). Thus, the ECD spectra of all four singly derivatized peptides showed fragments formed by $\mathrm{N}-\mathrm{C}_{\alpha}$ cleavages at both amide groups. In addition, cleavage of the $\mathrm{Ar}_{3} \mathrm{P}-\mathrm{CH}_{2}$ bond occurred that was accompanied by a proton transfer forming the most abundant $\mathrm{Ar}_{3} \mathrm{PH}^{+}$ cation.

The ECD mass spectrum of (TMPP-ac-GR $+\mathrm{H})^{2+}$ $\left(5^{2+}\right)$ showed fragments at $\mathrm{m} / \mathrm{z} 804$ (loss of $\mathrm{H}$ ), 717 (loss of $\mathrm{C}_{3} \mathrm{H}_{10} \mathrm{~N}_{3}$ from the Arg side-chain), 647 ( $c_{1}$ fragment, loss of $\mathrm{C}_{6} \mathrm{H}_{12} \mathrm{~N}_{3} \mathrm{O}_{2}$ ), 638 (loss of trimethoxyphenyl radical), $590\left(c_{0}\right), 533\left(\mathrm{Ar}_{3} \mathrm{PH}^{+}\right)$, and 470 (loss of $\mathrm{CH}_{3} \mathrm{OH}+$ $\mathrm{OCH}_{3}$ from $\mathrm{Ar}_{3} \mathrm{PH}^{+}$) (Figure 2).

The absence of charge reduced (TMPP-ac-peptide + $\mathrm{H})^{+\bullet}$ ions from GK, KG, AK, KA, and GR was consistent with the natural isotope abundances in the pertinent $m / z$ 776-778 and 790-793 ion groups. For example, the $[\mathrm{A}+1] /[\mathrm{A}]$ abundance ratios $[33]$ for $[\mathrm{m} / \mathrm{z} 791] /[\mathrm{m} / \mathrm{z}$ 790] from AK and KA (measured as 0.392 and 0.374, respectively) were close to those in the doubly-charged precursors, $[\mathrm{m} / \mathrm{z} 396] /[\mathrm{m} / \mathrm{z} 395.5]=0.448$ and 0.396 for $\mathrm{AK}$ and KA, respectively. The theoretical [A + 1]/[A]

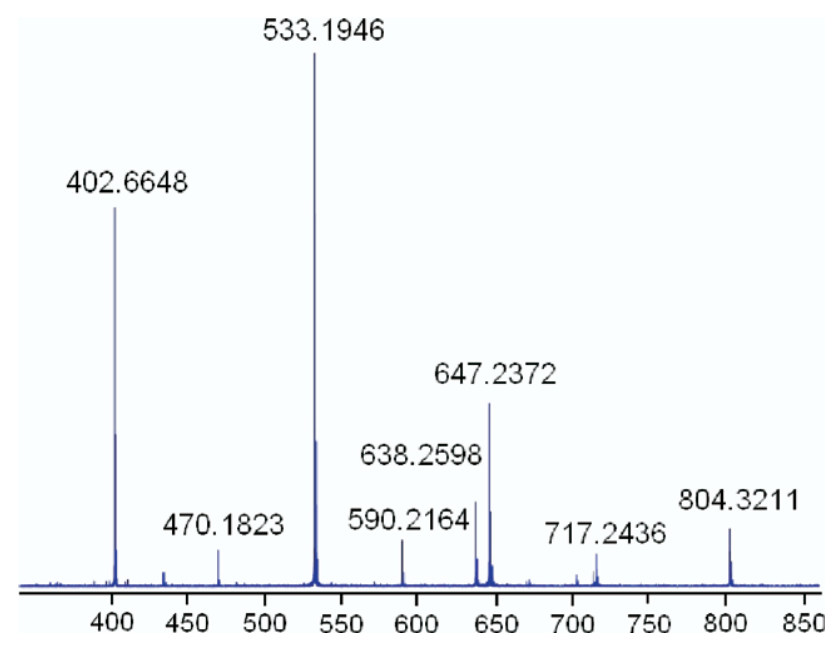

Figure 2. ECD spectrum of (TMPP-ac-GR $+\mathrm{H})^{2+}\left(5^{2+}\right)$ at $m / z$ 402.6648 .

ratio for $\mathrm{C}_{38} \mathrm{H}_{54} \mathrm{~N}_{3} \mathrm{O}_{13} \mathrm{P}$ is 0.443 . The data indicated that the contributions of (TMPP-ac-peptide $+\mathrm{H})^{+\cdot}$ at the pertinent $\mathrm{m} / \mathrm{z}$ values were negligible and the peaks could be assigned to the natural isotope satellites.

\section{CID Spectra}

To sort out electron-based and charge-driven dissociations upon electron capture, the ECD spectra were compared to collision-induced dissociation (CID) spectra of $(\text { TMPP-ac-peptide }+\mathrm{H})^{2+}$ and (TMPP-ac-peptide) ${ }^{+}$ions,

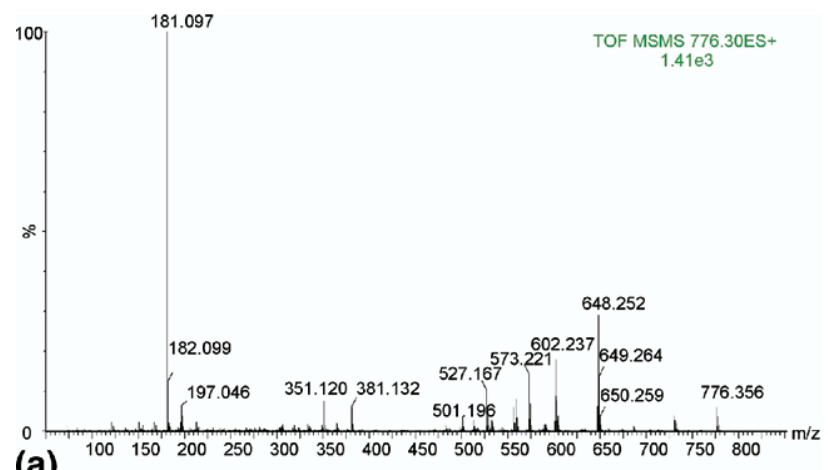

(a)

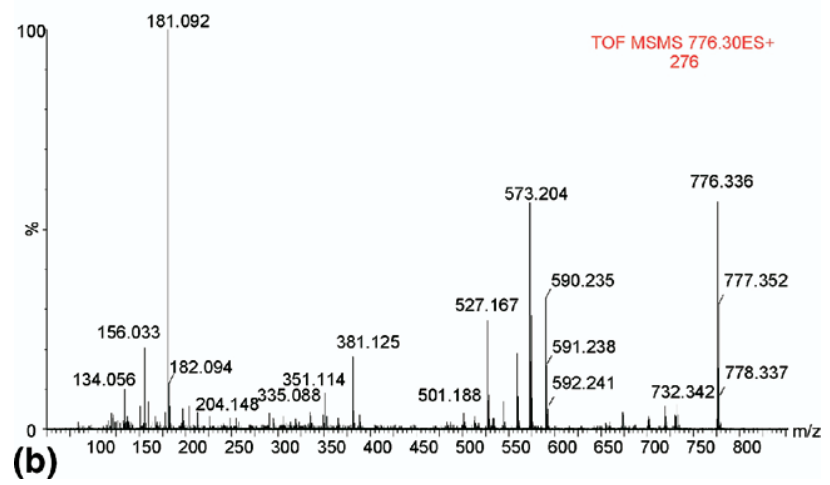

Figure 3. Collision-induced dissociation mass spectra of (a) $(\mathrm{TMPP}-\mathrm{ac}-\mathrm{GK})^{+}$and (b) (TMPP-ac-KG) ${ }^{+}$ions at $\mathrm{m} / \mathrm{z} 776.33$. 
as shown for GK and KG (Figure 3a, b). The CID spectrum of the (TMPP-ac-GK) ${ }^{+}$ion at $m / z 776$ (Figure 3a) showed a number of fragments that indicated extensive rearrangements upon collisional activation. Loss of the C-terminal amino acid (lysine $\mathrm{C}_{6} \mathrm{H}_{12} \mathrm{~N}_{2} \mathrm{O}$ ) $(\mathrm{m} / \mathrm{z} 648$ and 662 for GK and AK, respectively), as well as formation of $\boldsymbol{a}_{1}$ ions $(\mathrm{m} / \mathrm{z} 602$ and 616 for GK and AK, respectively) were observed in the spectra. Both fragmentations have been previously reported for singly charged TMPP peptide derivatives [17]. The spectra also showed fragment ions originating from the $\mathrm{Ar}_{3} \mathrm{P}^{+} \mathrm{CH}_{2} \mathrm{CONH}$ moiety, e.g., $\mathrm{Ar}_{3} \mathrm{PCH}=\mathrm{C}=\mathrm{O}^{+}(\mathrm{m} / \mathrm{z}$ 573), $m / z$ 527, 381, 351, and $\mathrm{ArPCH}_{2}{ }^{+}$(m/z 181). The latter fragments are typical of triarylphosphonium ions, as reported previously [34a].

CID of the (TMPP-ac-KG) ${ }^{+}$ion at $m / z 776$ (Figure $3 b$ ) showed elimination of a $\mathrm{C}_{8} \mathrm{H}_{14} \mathrm{~N}_{2} \mathrm{O}_{3}$ fragment $(\mathrm{m} / z$ 590), and the above-listed arylphosphonium fragment ions. The CID spectra of the (TMPP-ac-peptide $+\mathrm{H})^{2+}$ ions showed essentially the same dissociations as did the (TMPP-ac-peptide) $^{+}$ions but also involved protondriven formation of lysine $\boldsymbol{y}_{1}$ ions.

The important conclusion from the comparison of the ECD and CID spectra was that they mostly contained different fragment ions and thus were mutually exclusive. We note that there is a coincidental overlap at $\mathrm{m} / z 590$ due to the formation of the $\mathrm{Ar}_{3} \mathrm{P}^{+} \mathrm{CH}_{2} \mathrm{CONH}_{2}$ fragment ion by both charge-driven or charge-remote dissociation of (TMPP-ac-KG) ${ }^{+}$and (TMPP-ac-KA) ${ }^{+}$on the one hand, and electron-induced dissociation of $(\text { TMPP-ac-KG }+\mathrm{H})^{2+}$ and (TMPP-ac-KA $\left.+\mathrm{H}\right)^{2+}$ on the other. Note, however, that ion dissociations of the $(\text { TMPP-ac-GK }+\mathrm{H})^{2+}$ and (TMPP-ac-AK $\left.+\mathrm{H}\right)^{2+}$ ions did not produce the $m / z 590$ fragment ions at all, and so their presence in the corresponding ECD spectra must be due to exclusive electron-induced dissociations. The relative intensities of the $m / z 590 c_{0}$ ions, expressed as $\left[c_{0}\right] /[\text { (TMPP-ac-peptide }]^{+}$ratios, were greater for KG than for GK (1.7 and 0.5, respectively) and also for KA than AK (1.0 and 0.77 , respectively), which indicated that a fraction of the $m / z 590$ fragment ions from KG and KA could be formed by consecutive dissociations of the primary (TMPP-ac-peptide) ${ }^{+}$fragments from ECD, as indicated by the pertinent CID spectra.

Derivatization of the lysine amino group in (TMPPac-peptide-ac-TMPP) ${ }^{2+}$ had a substantial effect on the ECD mass spectra. As already mentioned, the presence of the second TMPP-ac group reduced the electron capture efficiency by a factor of two. Even more remarkably, ECD of (TMPP-ac-peptide-ac-TMPP) ${ }^{2+}$ ions did not result in peptide backbone dissociations, as illustrated with the GK and KG-derived ions, $6^{2+}$ and $7^{2+}$, respectively (Figure 4a, b). Although the chargereduced ions dissociated completely and no peaks of

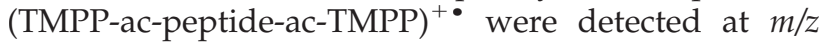
1349 for GK and KG, the observed fragments were due to loss of 2,4,6-trimethoxyphenyl radicals $(\mathrm{m} / \mathrm{z} 1182)$ and the $\mathrm{Ar}_{3} \mathrm{P}$ molecules $(\mathrm{m} / \mathrm{z}$ 817) and consecutive dissociations of the latter primary fragment ions. Interesting is

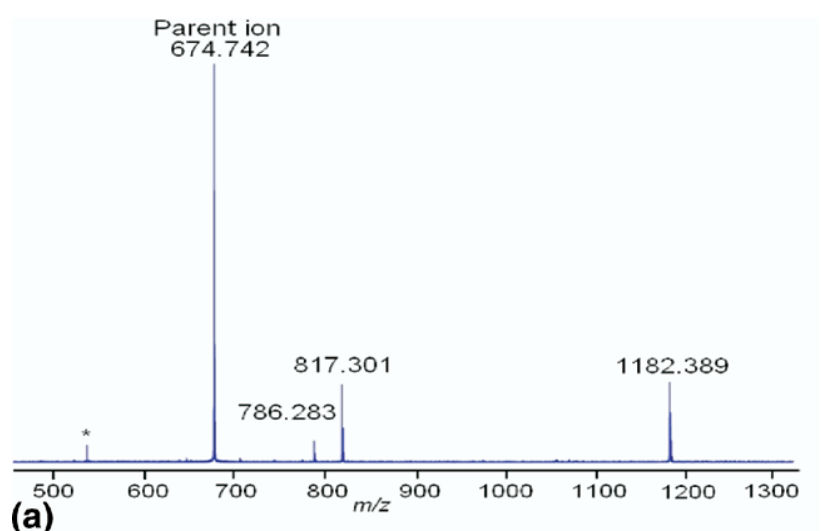

(a)

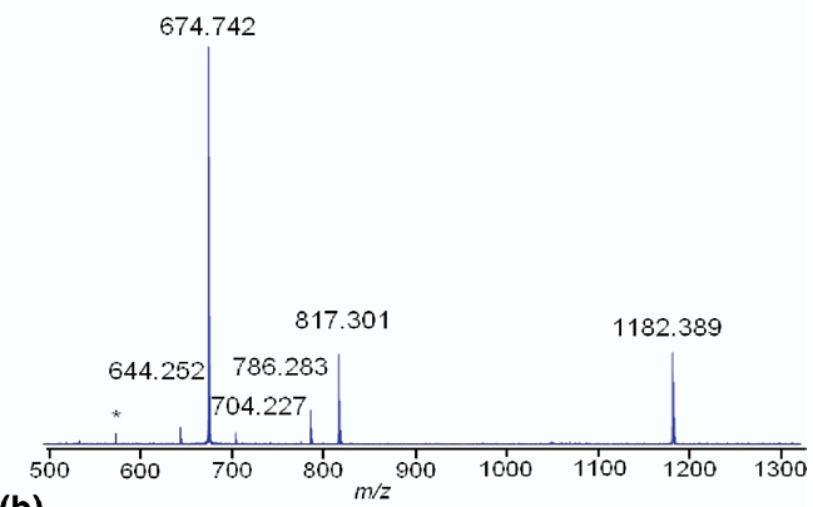

(b)

Figure 4. Electron-capture dissociation mass spectra of (a) (TMPPac-GK-ac-TMPP) $)^{2+}\left(6^{2+}\right)$ and (b) (TMPP-ac-KG-ac-TMPP) $)^{2+}\left(7^{2+}\right)$ precursor ions at $m / z 674.742$. Noise peaks are marked with asterisks.

the elimination of a $\mathrm{CH}_{3} \mathrm{O}$ radical from the $\mathrm{m} / \mathrm{z} 817$ ions, which indicates internal cyclization by attack of the $\cdot{ }^{\circ} \mathrm{CH}_{2} \mathrm{CO}-\mathrm{NH}$ radical at one of the remaining 2,4,6trimethoxyphenyl groups. The $m / z 644$ ions from $6^{2+}$, $7^{2+}$, and $\mathbf{9}^{2+}$ may correspond to $\mathrm{Ar}_{3} \mathrm{P}^{+} \mathrm{CH}_{2} \mathrm{CONHC}_{4} \mathrm{H}_{7}$ from the derivatized lysine side-chain. The fragment ions at $m / z 704$ for $\mathbf{6}^{2+}$ and $7^{2+}$ and $m / z 718$ for $\mathbf{9}^{2+}$ are complementary by mass to $m / z 644$ and may correspond to the cleavage of the same $C_{\alpha}-C_{\beta}$ lysine bond with an inverse hydrogen transfer onto the neutral fragment. Note that $m / z(644+704)=m / z 1348$ which is the mass of the whole GK or KG peptide minus $\mathrm{H}$. The measured exact $m / z$ ratios for ECD fragment ions from $\mathbf{6}^{2+}$ to $\mathbf{9}^{2+}$ are summarized in Table 2.

\section{Discussion}

ECD of the singly-derivatized (TMPP-ac-peptide $+\mathrm{H})^{2+}$ ions showed competitive loss of a hydrogen atom, $\mathrm{N}-\mathrm{C}_{\alpha}$ bond cleavages at both amide groups, and $\mathrm{P}-\mathrm{C}_{\alpha}$ bond dissociation in the phosphonium moiety that was accompanied by a proton transfer. The loss of $\mathrm{H}$ probably occurred as a result of electron attachment to the lysine ammonium group, by analogy with dissociations of other ammonium radicals [22] and peptide models $[8,13]$. Interestingly, ECD of (TMPP-ac-peptide $+\mathrm{H})^{2+}$ ions did not promote elimination of ammonia, which is 
Table 2. ECD spectra of (TMPP-ac-peptide-ac-TMPP) ${ }^{2+}$ ions

\begin{tabular}{|c|c|c|c|c|}
\hline \multirow[b]{2}{*}{ lons $^{a}$} & \multicolumn{4}{|c|}{ Peptide } \\
\hline & GK & KG & $A K$ & KA \\
\hline $\mathrm{M}^{2+}$ & $\begin{array}{c}\mathbf{6}^{\mathbf{2 +}} \\
674.7526 \\
674.7525^{\mathrm{a}}\end{array}$ & $\begin{array}{c}\mathbf{7}^{2+} \\
674.7527\end{array}$ & $\begin{array}{c}\mathbf{8}^{2+} \\
681.7606 \\
681.7603\end{array}$ & $\begin{array}{c}9^{2+} \\
681.7603\end{array}$ \\
\hline $\mathrm{M}^{+}$ & - & - & - & - \\
\hline$(M-A r)^{+b}$ & $\begin{array}{l}1182.4343 \\
1182.4341\end{array}$ & 1182.4345 & $\begin{array}{l}1196.4503 \\
1196.4497\end{array}$ & 1196.4497 \\
\hline$\left(\mathrm{M}-\mathrm{Ar}_{3} \mathrm{P}\right)^{+}$ & $\begin{array}{l}817.3185 \\
817.3187\end{array}$ & 817.3181 & $\begin{array}{l}831.3336 \\
831.3343\end{array}$ & 831.3343 \\
\hline$\left(\mathrm{M}-\mathrm{Ar}_{3} \mathrm{P}-\mathrm{CH}_{3} \mathrm{O}\right)^{+}$ & $\begin{array}{l}786.3006 \\
786.3003\end{array}$ & 786.2997 & $\begin{array}{l}800.3171 \\
800.3159\end{array}$ & 800.3165 \\
\hline$\left(\mathrm{M}-\mathrm{Ar}_{3} \mathrm{P}-\mathrm{CH}_{2} \mathrm{CONH}\left(\mathrm{CH}_{2}\right)_{4}\right)^{+}$ & $\begin{array}{l}704.2316 \\
704.2346\end{array}$ & 704.2339 & - & $\begin{array}{l}718.2508 \\
718.2503\end{array}$ \\
\hline $\mathrm{Ar}_{3} \mathrm{P}^{+} \mathrm{CH}_{2} \mathrm{CONH}\left(\mathrm{CH}_{2}\right)_{4}$ & $\begin{array}{l}644.2611 \\
644.2625\end{array}$ & 644.2623 & - & 644.2624 \\
\hline
\end{tabular}

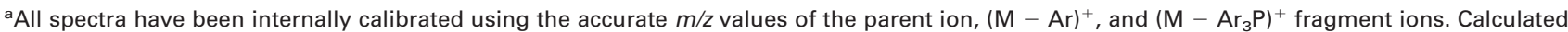
$\mathrm{m} / \mathrm{z}$ values in italics.

${ }^{\mathrm{b}} \mathrm{Ar}=2,4,6$-trimethoxyphenyl.

a common fragmentation upon ECD of non-derivatized peptide ions. Our observation is in line with the recent energy analysis of a peptide radical model which indicated that loss of ammonia from the side-chain ammonium group required a higher activation energy than did loss of an $\mathrm{H}$ atom, and so the former dissociation was disfavored [13]. In contrast, ECD-induced loss of ammonia is predicted to be extremely facile from protonated N-terminal ammonium groups [8], which are absent in the TMPP-derivatized peptides.

\section{Ion Structures}

To explain the dissociations of the $\mathrm{N}-\mathrm{C}_{\alpha}$ and $\mathrm{P}-\mathrm{C}_{\alpha}$ bonds, we performed extensive quantum chemistry calculations of ion and radical structures, electronic states, and dissociation energies. Since the TMPP group is rather large $\left(\mathrm{C}_{27} \mathrm{H}_{33} \mathrm{O}_{9} \mathrm{P}, 70\right.$ atoms $)$ it was simulated by $\mathrm{PH}_{3}$, triphenylphosphonium (TPP) and tris-(2,4,6-trihydroxyphenyl)phosphonium

(THPP) groups that were presumed to have electronic properties converging to those of TMPP. The intrinsic properties of the dipeptide moiety were studied for $(\mathrm{GK}+\mathrm{H})^{\bullet}$ and $(\mathrm{GR}+\mathrm{H})^{\bullet}$ radicals. The interaction between the phosphonium and protonated dipeptide moieties was modeled in conjugates that had $\mathrm{PH}_{3}-\mathrm{CH}_{2} \mathrm{CO}$ - (Struc-

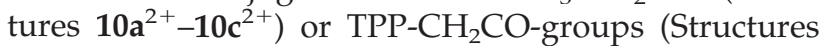
$\mathbf{1 1} \mathbf{a}^{2+}-\mathbf{1 1} \mathbf{c}^{2+}$ ) linked to the GK dipeptide (Figure 5).

The doubly charged ions $\mathbf{1 0}^{2+}$ and $\mathbf{1 1}^{2+}$ were each found to have more than one conformation corresponding to a local energy minimum. The lowest energy conformers $\mathbf{1 0 a ^ { 2 + }}$ and $\mathbf{1 1} \mathbf{a}^{2+}$ had the lysine side chain $\mathrm{NH}_{3}{ }^{+}$group hydrogen bonded to the carboxylate Cterminus. Higher-energy conformers $\mathbf{1 0} \mathbf{b}^{2+}$ and $\mathbf{1 1} \mathbf{b}^{2+}$ had the lysine side chain $\mathrm{NH}_{3}{ }^{+}$group hydrogen bonded to the Gly amide carbonyl. The calculated

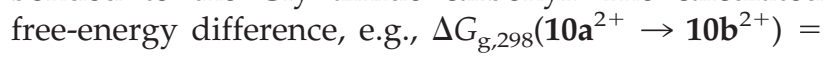

$32 \mathrm{~kJ} \mathrm{~mol}^{-1}$, clearly preferred the carboxylate-solvated conformer, and the free-energy difference further increased at higher temperatures, e.g., $\Delta G_{\mathrm{g}, 473}\left(\mathbf{1 0 a ^ { 2 + }} \rightarrow\right.$ $\mathbf{1 0 b}^{2+}$ ) $=33.6 \mathrm{~kJ} \mathrm{~mol}^{-1}$, due to the lower entropy of $\mathbf{1 0 b}^{2+}$. A conformer with a fully extended lysine sidechain was also found to be a local energy minimum $\left(\mathbf{1 0} \mathrm{c}^{2+}\right.$, Figure 5). However, Structure $\mathbf{1 0} \mathrm{c}^{2+}$ was less

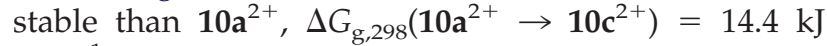
$\mathrm{mol}^{-1}$, indicating that the stabilization gained by intramolecular hydrogen bonding in conformer $\mathbf{1 0 a ^ { 2 + }}$ was more favorable than a decrease in Coulomb repulsion between the two charge sites in the more extended conformer $\mathbf{1 0} \mathrm{c}^{2+}$. Lysine hydrogen bonding to the $\mathrm{COOH}$ group is also preferred in $11^{2+}$, e.g., $\Delta G_{\mathrm{g}, 298}\left(\mathbf{1 1 a}^{2+} \rightarrow \mathbf{1 1 b}^{2+}\right)=20 \mathrm{~kJ} \mathrm{~mol}^{-1}$, and $\Delta G_{\mathrm{g}, 298}\left(\mathbf{1 1 a}^{2+} \rightarrow \mathbf{1 1 c}^{2+}\right)=31 \mathrm{~kJ} \mathrm{~mol}^{-1}$. Hence, we conclude that the calculated relative enthalpies and free energies for the model peptide conformers $10^{2+}$ and $\mathbf{1 1}^{\mathbf{2 +}}$ indicated that the C-terminal lysine ammonium group was most likely hydrogen bonded to the carboxyl group, not the amide carbonyls, in the most stable and thus most populated conformers of the (TMPP-acpeptide $+\mathrm{H})^{2+}$ dications $\mathbf{1}^{2+}$ and $3^{2+}$. The calculated $\Delta G_{g, 298}$ values give $99.7 \%$ of both $10 a^{2+}$ and $11 a^{2+}$ at equilibrium indicating substantial conformational homogeneity of the ion populations. Lysine hydrogen bonding in $2^{2+}, 4^{2+}$, and the arginine side-chain $\mathrm{H}$ bonding in $5^{2+}$ were not studied here.

Are the structures of the charge-tagged peptide dications relevant for those of standard peptide ions? To address this question, we note that the distance between the charge-carrying phosphonium and ammonium atoms in the most stable conformers $10 \mathbf{a}^{2+}$ and $\mathbf{1 1 a}^{2+}$ (13.14 and $13.22 \AA$, respectively, Figure 5) is comparable to or greater than the distance between the charge carrying arginine guanidinium and lysine ammonium groups in doubly protonated Substance $\mathrm{P}$ 

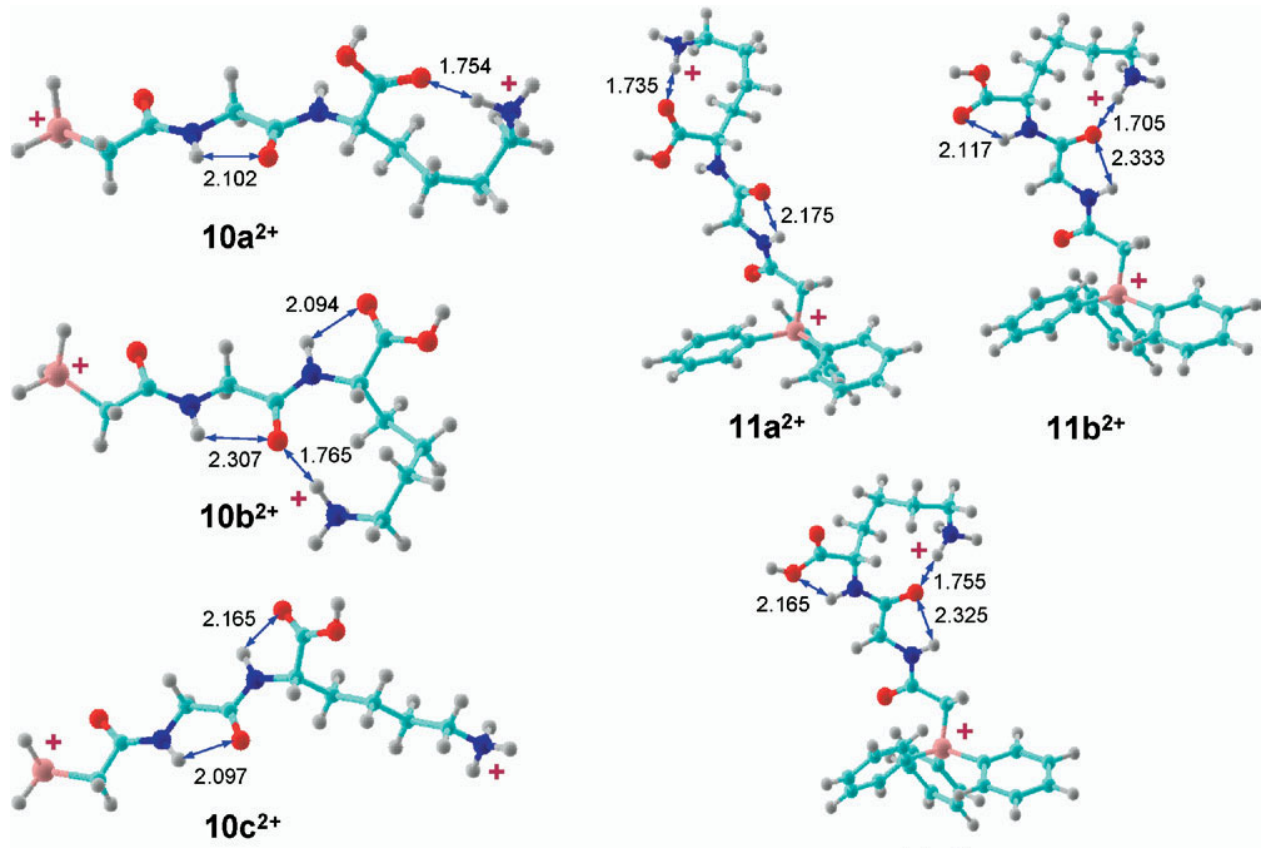

$11 b^{2+}$

$11 c^{2+}$

Figure 5. B3LYP/6-31+G(d,p) optimized structures of ion conformers $10 a^{2+}-10 c^{2+}$, and $11 a^{2+}-$ $11 \mathrm{c}^{2+}$. Double arrows indicate intramolecular hydrogen bonds in angstroms.

(11.2-12.0 A)), as documented by fully optimized structures of the RPKP motif (Figure S1, Supplementary Material section, which can be found on the electronic version of this article). Thus, the Coulomb repulsion between the charge sites in $10 \mathrm{a}^{2+}$ and $11 \mathrm{a}^{2+}$ is of a similar magnitude as in standard peptide ions used for ECD studies.

\section{Ion Recombination Energies}

Electron attachment to the doubly charged ions depends on the intrinsic recombination energies (RE) of the charged sites to reach the ground electronic state of the charge-reduced cation-radical. Because the charged sites are remote in the dications, they affect each other mainly by through-space Coulomb effects, which can be expressed by additive energy terms. We investigated the intrinsic group recombination energies in $(\mathrm{GK}+$ $\mathrm{H})^{+},(\mathrm{GGK}+\mathrm{H})^{2+},(\mathrm{GR}+\mathrm{H})^{+}$, THPP-CH $\mathrm{CONH}_{2}{ }^{+}$, and in a series of other phosphonium ions. The combined charge effects on the RE in the doubly charged ions were studied for $\left(\mathrm{PH}_{3} \mathrm{CH}_{2} \mathrm{CO}-\mathrm{GK}+\mathrm{H}\right)^{2+}$.

The intrinsic recombination energies (absolute values) of phosphonium ions decrease upon addition of phenyl or 2,4,6-trihydroxyphenyl and alkyl groups to the phosphorus atom to reach $\left|R_{\text {adiab }}\right|=3.07 \mathrm{eV}$ in $\mathrm{Ar}_{3} \mathrm{P}^{+} \mathrm{CH}_{2} \mathrm{CONH}_{2}(\mathrm{Ar}=$ 2,4,6-trihydroxyphenyl, THPP, Table 3). A further decrease by ca. $0.3 \mathrm{eV}$ can be expected upon replacing the phenol hydroxy groups in THPP by methoxy groups in TMPP, by analogy with the $0.3 \mathrm{eV}$ decrease in ionization energies in methoxybenzenes compared with those in phenols [34b]. Hence, the intrinsic recombination energy of TMPP is estimated to be as low as $\left|\mathrm{RE}_{\text {adiab }}\right| \approx 2.7 \mathrm{eV}$.

The $\mathrm{Ar}_{3} \mathrm{P}^{+} \mathrm{CH}_{2} \mathrm{CONH}$ group underwent only minor structural changes upon electron attachment. The optimized structures of the THPP- $\mathrm{CH}_{2} \mathrm{CONH}_{2}$ cation $\left(\mathbf{1 2}^{+}\right)$ and radical $\left(\mathbf{1 2}^{\circ}\right)$ are shown in Figure S2 (Supplementary Material). Both structures show essentially tetrahedral phosphorus atoms with a minor flattening of the $\mathrm{C}_{1}-\mathrm{C}_{2}-\mathrm{C}_{4}-\mathrm{P}$ base, which is due to steric repulsion of the aromatic rings. The $\mathrm{P}-\mathrm{CH}_{2}$ bond length practically did

Table 3. Calculated ion-electron recombination energies

\begin{tabular}{|c|c|c|c|}
\hline \multirow[b]{2}{*}{ Species } & \multicolumn{3}{|c|}{ Recombination energy ${ }^{a}$} \\
\hline & $\begin{array}{c}\text { B3LYP/6-311 } \\
++\mathrm{G}(2 \mathrm{~d}, \mathrm{p})\end{array}$ & PMP2 & B3-PMP2 \\
\hline $\mathrm{PH}_{4}^{+}$ & 5.92 & 5.47 & $5.70(5.70)^{\mathrm{b}}$ \\
\hline $\mathrm{Ph}_{3} \mathrm{PH}^{+}$ & 4.10 & 4.88 & 4.49 \\
\hline $\mathrm{Ph}_{3} \mathrm{PCH}_{3}{ }^{+}$ & 3.82 & 3.50 & 3.66 \\
\hline $\mathrm{Ph}_{3} \mathrm{PCH}_{2} \mathrm{CONH}_{2}^{+}$ & 3.85 & & \\
\hline $\mathrm{Ar}_{3} \mathrm{PH}^{+\mathrm{c}}$ & 3.15 & & \\
\hline $\mathrm{Ar}_{3} \mathrm{PCH}_{2} \mathrm{CONH}_{2}^{+\mathrm{c}}$ & 3.07 & & \\
\hline$(\mathrm{GK}+\mathrm{H})^{+}$ & $4.37^{\mathrm{d}}(3.30)^{\mathrm{e}}$ & $4.12^{\mathrm{d}}(3.00)^{\mathrm{e}}$ & $4.24^{\mathrm{d}}(3.15)^{\mathrm{e}}$ \\
\hline$(\mathrm{GR}+\mathrm{H})^{+}$ & $3.87(2.98)^{\mathrm{e}}$ & $3.63(2.64)^{\mathrm{e}}$ & $3.75(2.81)^{\mathrm{e}}$ \\
\hline$(\mathrm{GGK}+2 \mathrm{H})^{2+}$ & $5.76(5.31)^{\mathrm{e}}$ & $5.16(4.56)^{\mathrm{e}}$ & $5.46(4.94)^{\mathrm{e}}$ \\
\hline
\end{tabular}

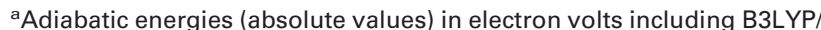
$6-31+G(d, p)$ zero-point energy corrections.

${ }^{b}$ Reference adiabatic recombination energy from single-point CCSD(T)/ aug-cc-pVTZ calculations.

${ }^{\mathrm{C}} \mathrm{Ar}=2,4,6$-trihydroxyphenyl (THPP).

Including radical rearrangement in the lysine residue by $\mathrm{H}$ atom migration onto the $\mathrm{COOH}$ group.

eVertical recombination energies. 


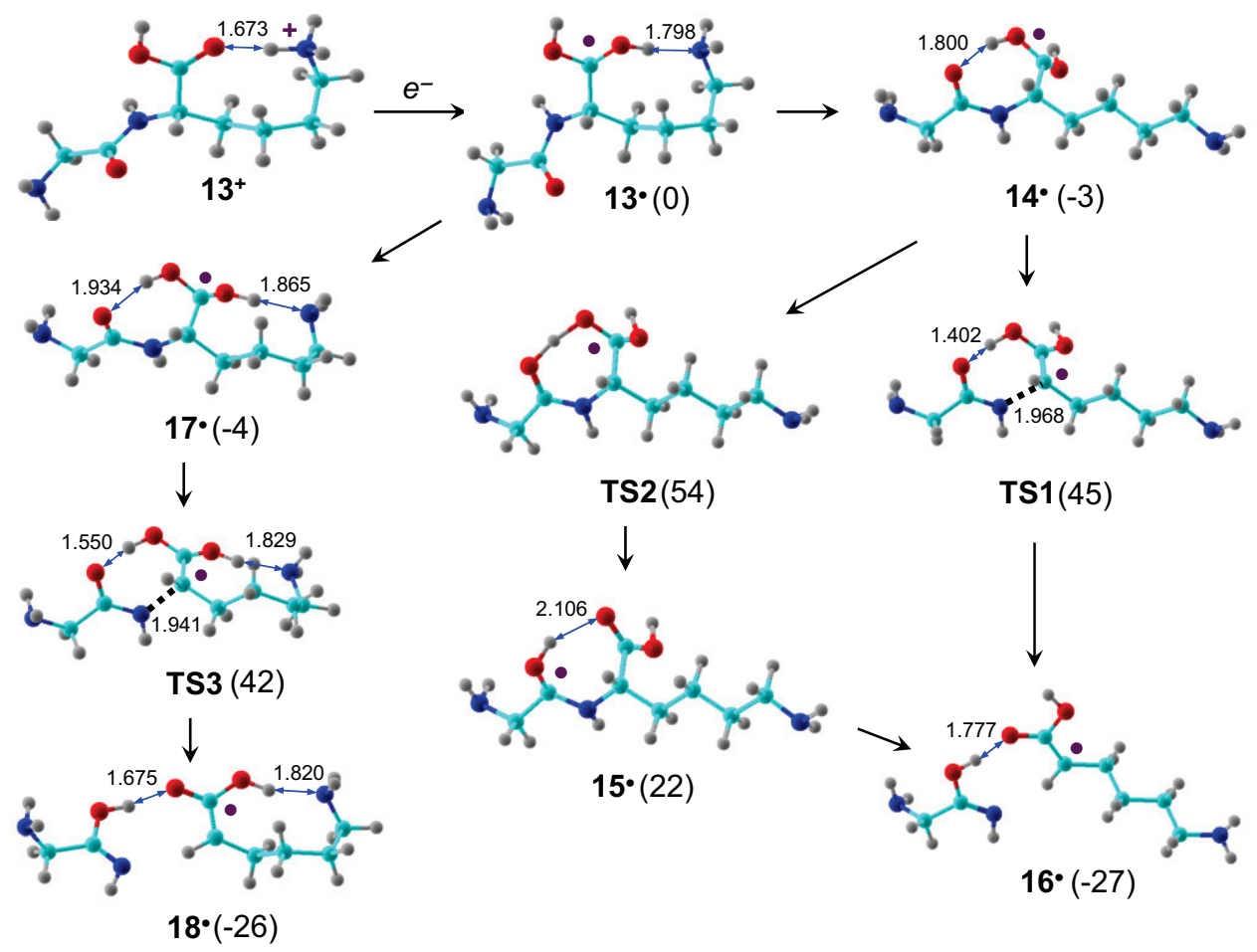

Scheme 3

not change upon electron attachment whereas the $\mathrm{P}-\mathrm{C}_{1}$ aryl bond was extended by $0.073 \AA$ in the radical (Figure S2). Note that tetravalent phosphoranyl radicals typically prefer trigonal bipyramidal geometries about the $\mathrm{sp}^{3} \mathrm{~d}$ hybridized $\mathrm{P}$ atom in which the odd-electron containing orbital assumes an equatorial or axial position [35]. Thus, the near-tetrahedral Structure of $\mathbf{1 2}$ indicates that the electron is in a large part delocalized over the aromatic $\pi$-orbital system in triaryl phosphonium radicals.

The intrinsic recombination energy of the protonated GK moiety can be estimated from the calculated vertical $\mathrm{RE}$ as $3.15 \mathrm{eV}$. It is noteworthy that the $(\mathrm{GK}+\mathrm{H})^{\bullet}$ radical formed by electron attachment to the $(\mathrm{GK}+\mathrm{H})^{+}$ cation is not a local energy minimum, but it rearranges by an exothermic $\mathrm{H}$ atom migration to the $\mathrm{COOH}$ group to form a stable dihydroxycarbinyl radical $\left(\mathbf{1 3}^{\circ}\right.$, Scheme 3$)$. Thus, when including the change in energy due to the rearrangement, one obtains $\left|\mathrm{RE}_{\mathrm{adiab}}\right|(\mathrm{GK}+\mathrm{H})^{+}=$ $4.24 \mathrm{eV}$ (Table 3). The effect on the RE of the other charge can be estimated from the comparison of the vertical $\mathrm{RE}$ of $(\mathrm{GK}+\mathrm{H})^{+}(3.15 \mathrm{eV})$ and $\mathbf{1 0 \mathrm { a } ^ { 2 + }}(4.82)$ as $\Delta \mathrm{RE}=4.82-3.15=1.67 \mathrm{eV}$. Again, the adiabatic RE of $10 \mathrm{a}^{2+}$ was less useful, because upon attachment the electron ended up in the $\mathrm{PH}_{3}$ group in the ground electronic state of the cation-radical and caused substantial structure changes due to an $\mathrm{sp}^{3} \rightarrow \mathrm{sp}^{3} \mathrm{~d}$ bond rehybridization around the phosphorus atom. From the combined intrinsic recombination energies and charge effects we estimate the vertical recombination energies of $\mathbf{1}^{2+}, 2^{2+}, 3^{2+}$, and $4^{2+}$ to be close to $3.15+$ $1.67=4.82 \mathrm{eV}$ when producing lysine ammonium radicals, whereas the charge remains in the $\mathrm{Ar}_{3} \mathrm{P}$ group in the ground electronic state of the cation-radical.

In contrast, the vertical recombination energy of the $(\mathrm{GR}+\mathrm{H})^{+}$cation $\left(\mathbf{1 9}^{+}\right.$, Scheme 4$)$ was calculated as $\mathrm{RE}_{\mathrm{vert}}=2.81 \mathrm{eV}$ for electron attachment to the guanidinium group. Hence, the intrinsic recombination energy of the guanidinium group was close to that of TMPP. This indicates that electron attachment to

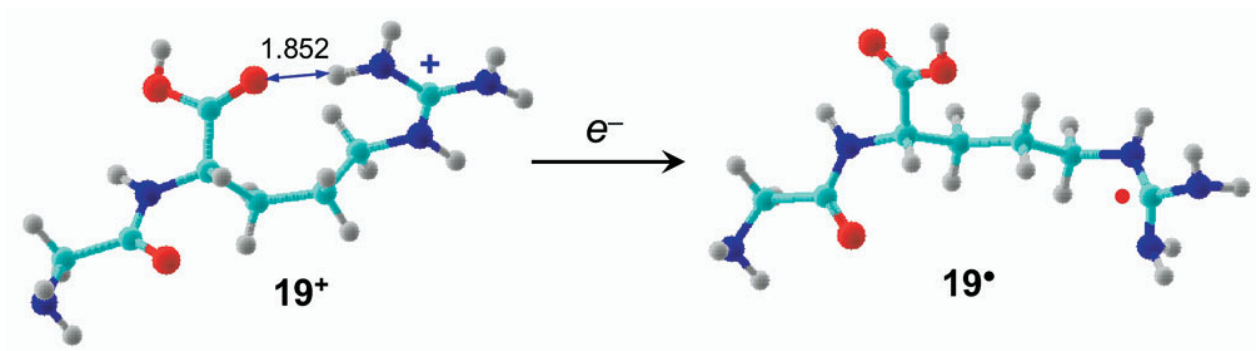

Scheme 4 
$(\text { TMPP-ac-GR }+\mathrm{H})^{2+}$ could occur in overlapping manifolds of near-degenerate states, one delocalized over the TMPP group and the other in the arginine guanidinium group. Note the large difference between the optimized cation and radical structure (Scheme 4) that results in large Franck-Condon effects in electron capture, as discussed later.

\section{Discussion of Reaction Mechanisms}

We now discuss the possible mechanisms for the formation of $c_{0}$ and $c_{1}$ fragments from the charge-tagged GK peptide ions. Application of the Cornell mechanism to ECD in $\mathbf{1}^{2+}-4^{2+}$ would require hydrogen atom transfer from the protonated group to one of the amide carbonyls. However, the ion conformations indicate that the vast majority of GK dications have the charged lysine side chains internally solvated by the carboxylate, not amide groups. Can the ions rearrange their conformations during or after electron capture to enable a hydrogen transfer to the amide groups according to the Cornell mechanism?

We address this question by analyzing $\mathrm{H}$-atom migrations following electron capture in simpler systems, e.g., $(\mathrm{GK}+\mathrm{H})^{+}+\mathrm{e}^{-} \rightarrow(\mathrm{GK}+\mathrm{H})^{\bullet}$ and $(\mathrm{GGK}+2 \mathrm{H})^{2+}+$ $\mathrm{e}^{-} \rightarrow(\mathrm{GGK}+2 \mathrm{H})^{+\bullet}$, that are amenable to good quality quantum theory calculations of their ground doublet electronic states. The $(\mathrm{GK}+\mathrm{H})^{+}$cation $\left(\mathbf{1 3}^{+}\right.$, Scheme $\left.\mathbf{3}\right)$ has the lysine ammonium group internally solvated by the carboxyl group, as in the dominant conformers of charge-tagged ions $\mathbf{1 0}^{2+}$ and $\mathbf{1 1}^{2+}$. Upon electron attachment, the ground doublet electronic state of the incipient radical undergoes spontaneous barrierless rearrangement by $\mathrm{H}$-atom migration to the carboxyl carbonyl forming the dihydroxycarbinyl radical $13^{\circ}$. The fact that the incipient lysine ammonium radical is not a local energy minimum implies that it cannot undergo a conformational rearrangement to deliver the hydrogen atom to the amide group. Note that conformational changes in gas-phase ions and radicals require small yet finite activation energies about 7 to $15 \mathrm{~kJ} \mathrm{~mol}^{-1}$ that limit the rate constants to ca. $10^{12} \mathrm{~s}^{-1}$. In contrast, the $\mathrm{H}$-atom migration forming $13^{\circ}$ occurs on a repulsive potential energy surface within one $\mathrm{N}-\mathrm{H}$ vibration $\left(\nu(\mathrm{N}-\mathrm{H})=2859 \mathrm{~cm}^{-1}\right)$, which limits the lifetime of the incipient ammonium radical to less than one vibrational period, $\mathrm{T}=1 /(2 \pi \mathrm{c} \nu)=2 \times 10^{-15} \mathrm{~s}$. Hence, no kinetic process that has to overcome a finite energy barrier can compete with this barrierless isomerization.

We now describe that the spontaneous rearrangement upon electron attachment which moves the ammonium proton to the $\mathrm{COOH}$ group can trigger the formation of the $c_{1}$ fragments through a relay-type mechanism $[6 \mathrm{~b}, 6 \mathrm{~d}]$ proceeding on the ground electronic state, as studied for $\left(\mathbf{1 3}^{\circ}\right)$, and shown in Scheme 3 under the assumption that the presence of the remote charge in the triarylphosphonium group would represent only a minor perturbation of the radical system [14, see below]. Also shown in Scheme 3 are the radical relative energies in $\mathrm{kJ} \mathrm{mol}^{-1}$ (values in parentheses).

The dihydroxycarbinyl radical $\left(\mathbf{1 3}^{\circ}\right)$ produced by electron capture in $13^{+}$can, in principle, undergo a $\beta$-fission of the $\mathrm{N}-\mathrm{C}_{\alpha}$ bond. However, a direct cleavage of this bond leads to an amidyl radical product (not shown in Scheme 3), which is a high-energy species. Energetically more plausible pathways were found that involved practically thermoneutral conformational changes by which the HO-C-OH group rotated to become hydrogen bonded to the $c_{1}$-amide carbonyl, as in intermediates $14^{\circ}$ and $\mathbf{1 7}^{\circ}$ (Scheme 3 ). $\mathrm{N}-\mathrm{C}_{\alpha}$ bond cleavages in the latter radicals require only low TS energies in the pertinent transition states TS1 and TS3 to exothermically form dipole-dipole complexes $16^{\circ}$ and $18^{\circ}$, respectively, that can eventually dissociate to convergently form the $c_{1}$ fragment.

Since the $\mathrm{N}-\mathrm{C}_{\alpha}$ bond dissociations in $14^{\circ}$ and $17^{\circ}$ are accompanied by proton migration to the incipient $c_{1}$ fragments, a question arises if the hydrogen atom can migrate to the amide group in a relay-type step-wise mechanism to promote dissociation of an $\mathrm{N}-\mathrm{C}_{c x}$ bond that was initially remote from the radical site, e.g., in the formation of the $c_{0}$ ions. This was studied with $14^{\bullet}$ for which we found a transition-state (TS2) for $\mathrm{H}$-atom transfer to the proximate amide carbonyl to give aminoketyl intermediate $\mathbf{1 5}^{\circ}$ (Scheme 3). However, the TS2 energy was above those for TS1 and TS3, which kinetically disfavored the $\mathrm{H}$-atom migration. This was corroborated by RRKM calculations (Figure S3, Supplementary Material) which showed that the $\mathrm{N}-\mathrm{C}_{\alpha}$ bond dissociations in $14^{\circ}$ and $17^{\circ}$ were 2.5 - to 12 -fold faster than the $\mathrm{H}$-atom migration over a $50-350 \mathrm{~kJ} \mathrm{~mol}^{-1}$ range of radical internal energies.

$\mathrm{H}$-atom migration to a more remote amide carbonyl in the presence of charge was studied for electron attachment to $(\mathrm{GGK}+2 \mathrm{H})^{2+}$ cations $\mathbf{2 0}^{+}$and $\mathbf{2 1}^{+}$ (Scheme 5). By analogy with $13^{\circ}$, electron capture in the ground doublet state of $\mathbf{2 1}^{+\boldsymbol{\bullet}}$ results in a barrierless $\mathrm{H}$-atom migration to the $\mathrm{COOH}$ group forming the dihydroxycarbinyl cation radical $\mathbf{2 2}^{+}$in which the residual charge is located in the internally solvated $\mathrm{N}$-terminal ammonium group. However, $\mathrm{H}$-atom transfer onto the more remote amide carbonyl requires $90 \mathrm{~kJ}$ $\mathrm{mol}^{-1}$ in the transition-state (TS4) and thus is even less favorable than a transfer to the neighboring amide group (TS2). One might note that in addition to having an activation energy that exceeds those typically found for $\mathrm{N}-\mathrm{C}_{\alpha}$ bond dissociations $[9,10]$, the $\mathrm{H}$-atom migration from the dihydroxycarbinyl radical to a remote amide carbonyl would also be disfavored entropically.

The possible effect on the transition states for $\mathrm{H}$ atom migration of the residual charge was studied for the extreme cases of no charge (as in TS2) and a very close charge (as in TS4, Scheme 5). NPA atomic charge densities at the recipient amide group were calculated for the reactants, transition states, and products. For the $14^{\circ} \rightarrow$ TS2 $\rightarrow 15^{\circ}$ migration, the charge in the recipient amide group goes from 0.41 in $\mathbf{1 4}^{\bullet}$ through 0.50 in TS2 


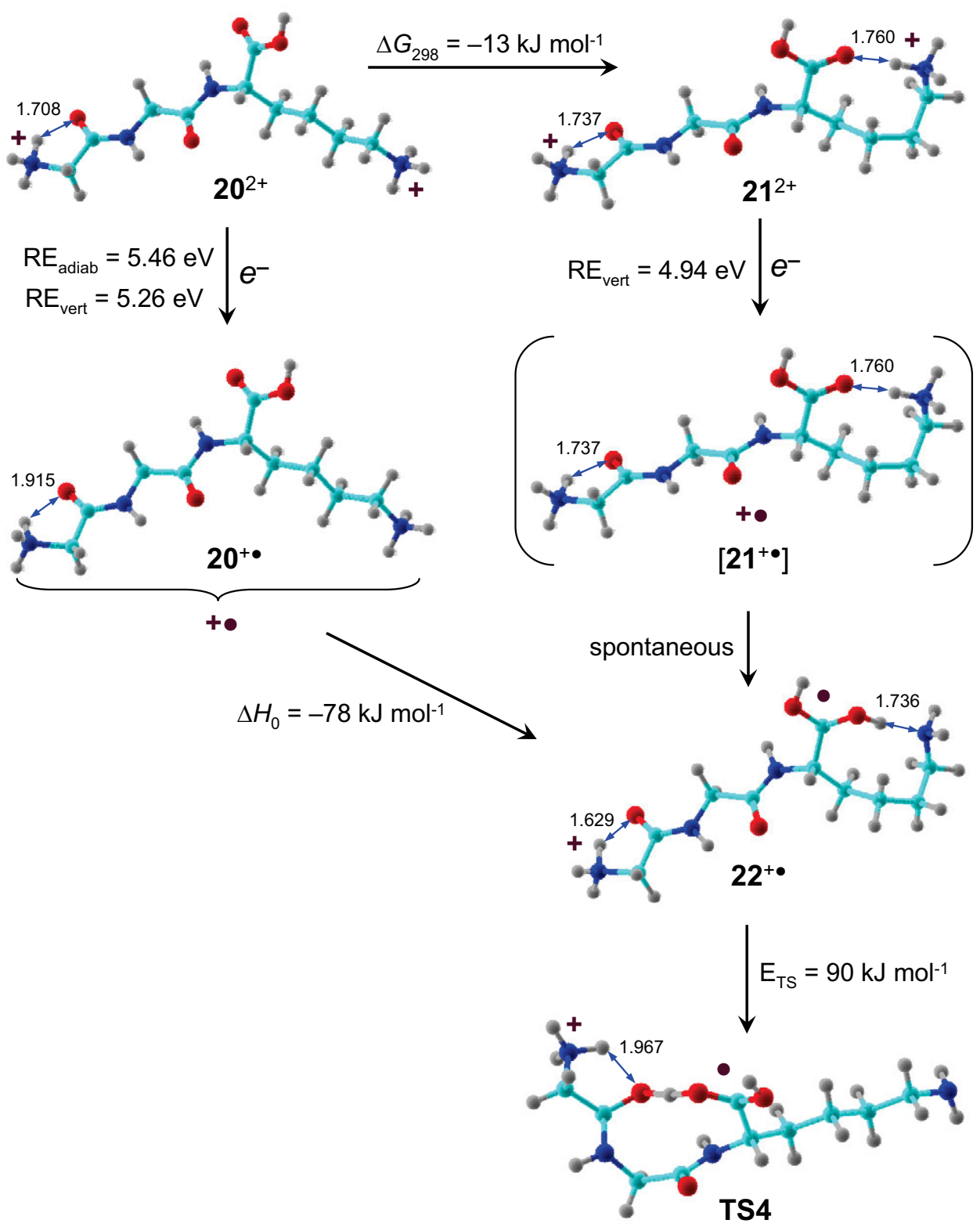

Scheme 5

to -0.01 in $15^{\circ}$. Thus, while the product $\left(\mathbf{1 5}^{\circ}\right)$ could be expected to be stabilized in the presence of a remote positive charge at the N-terminus, stabilization of the transition-state would be marginal. In the reaction $22^{+\bullet} \rightarrow$ TS4, the charge in the N-terminal amide group goes from 0.09 to -0.52 , indicating a polarizing effect of the proximate charge on the charge distribution in the transition-state. In spite of this favorable effect, the transition-state energy for the hydrogen migration is substantial, especially in comparison with the energetically much more favored $\mathrm{N}-\mathrm{C}_{\alpha}$ bond dissociations $[9,10]$. These model calculations strongly indicate that ground electronic states of charge-reduced ions may not have low-energy hydrogen migration pathways to produce intermediates that would allow for kinetically competitive bond cleavages at remote amide groups.
It may be noted that while the hydrogen transfer from internally solvated lysine ammonium groups is spontaneous upon electron attachment, the guanidinium groups in arginine residues are poor $\mathrm{H}$-atom donors and prefer other dissociation pathways [11]. Hence, the formation of the $c_{1}$ fragment by the abovedescribed relay mechanism may not be competitive in the GR peptide ions.

As discussed above, the formation of the $c_{0}$ ions requires a cleavage of the $\mathrm{N}-\mathrm{C}_{\alpha}$ bond which is remote from both the lysine $\mathrm{NH}_{3}{ }^{+}$group in the precursor dication and from the dihydroxycarbinyl radical site in the putative intermediates (e.g., $\mathbf{1 3}^{\circ}$ ), and thus this cleavage is difficult to rationalize by the same, relaytype, mechanism that was discussed above for the formation of the $c_{1}$ ion. In keeping with the UW 


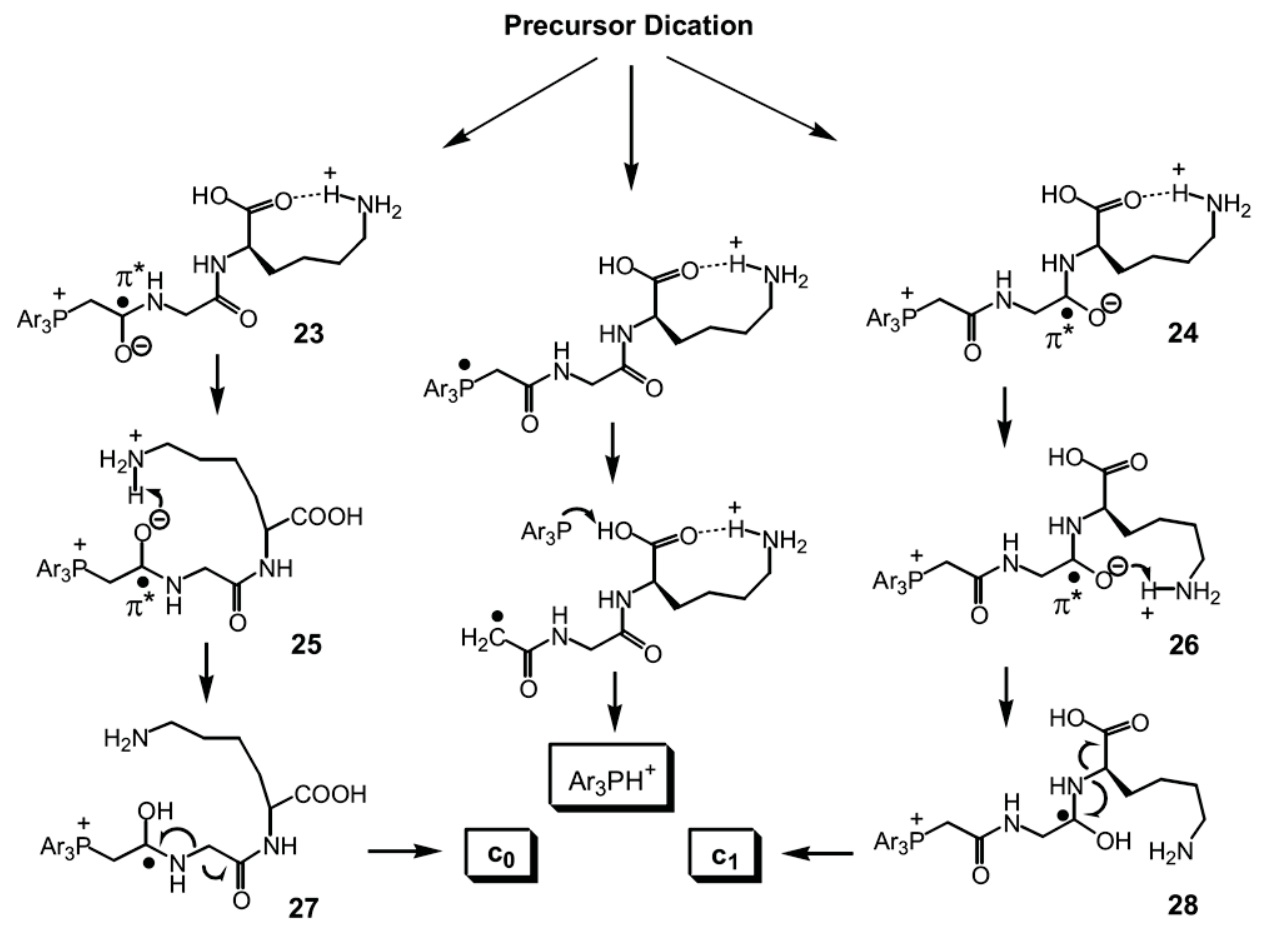

Scheme 6

mechanism, one can presume that, in a fraction of dications, the electron enters a $\pi^{*}$ amide orbital corresponding to an excited electronic state of the chargereduced ion. The electron in the $\pi^{*}$ state is stabilized by Coulomb interaction with the ammonium and phosphonium charges, e.g., Structures 23 and 24 (Scheme 6). The reaction sequence in Scheme 6 involves a conformational change in 23 and 24 to bring the lysine ammonium or carboxyl groups to the negatively charged amidyl oxygens $(25,26)$, followed by exothermic proton migration $[8,13]$ forming the intermediate aminoketyl radicals $\mathbf{2 7}$ and $\mathbf{2 8}$. The latter are expected to readily dissociate by $\mathrm{N}-\mathrm{C}_{\alpha}$ bond cleavage $[9,10]$ giving ions $c_{\mathrm{o}}$ and $c_{1}$, respectively. It should be noted that the UW mechanism depicted in Scheme 6 still lacks on several details that are the subject of current investigations. For example, electron attachment to the particular $\pi^{*}$ amide orbital can be mediated by transfer through orbitals in one or more intermediate excited electronic states, and the cross sections for such electron-transfer are unknown $[15 a, b]$. Furthermore, the conformational properties of excited electronic states are difficult to investigate even for simple peptide models [15c], and so information on such potential energy surfaces is currently lacking.

Figure 6 shows the electronic states of the chargereduced analog $10 \mathrm{a}^{+} \cdot$. The lowest electronic states $X, A$, and $\boldsymbol{B}$ correspond to the positive and negative combinations of the phosphonium $4 \mathrm{~s}$ and ammonium $3 \mathrm{~s}$ Rydberg-like orbitals in combination with a $\pi^{*}$ orbital of the $\mathrm{COOH}$ group. The nodal properties of the frontier molecular orbitals in the $X, A$, and $B$ states are favorable for a transfer of the ammonium proton onto the $\mathrm{COOH}$ group, which is barrierless when the electron is attached to the ammonium group and can move to $\mathrm{COOH}$ by proton-coupled electron-transfer [36]. In contrast, the low-lying $\boldsymbol{C}, \boldsymbol{D}$, and $\boldsymbol{E}$ states at $0.32,0.50$, and $0.70 \mathrm{eV}$ excitation energies show substantial electron density in the relevant $\mathrm{P}-\mathrm{CH}_{2} \mathrm{CO}-\mathrm{NH}$ amide group that can trigger its further reactions according to the UW mechanism. Note that the UW mechanism can also be used to explain the formation of the $c_{1}$ ion. Electron capture in the charge-stabilized $G$ state of a $0.93 \mathrm{eV}$ excitation energy produces a reactive intermediate that after conformational change of the lysine chain can undergo exothermic proton transfer forming aminoketyl radical 28. A N-C $\mathrm{C}_{\alpha}$ bond cleavage in the latter then gives ion $c_{1}$.

Excited electronic states can be used to explain the formation of the abundant $\mathrm{Ar}_{3} \mathrm{PH}^{+}$ions ( $m / z$ 533), which requires a dissociation of the $\mathrm{P}-\mathrm{C}_{\alpha}$ bond which is promoted by electron attachment to the phosphonium ion [35]. The recombination energy of the $\mathrm{Ar}_{3} \mathrm{P}^{+}$group in $\mathbf{1}^{2+}$ and $3^{2+}$ is estimated to be composed of its intrinsic RE $(2.7 \mathrm{eV})$ and the Coulomb term $(1.67 \mathrm{eV})$ to give $\left|\mathrm{RE}_{\text {adiab }}\right| \approx 4.4 \mathrm{eV}$, which is ca. 0.4 to $0.5 \mathrm{eV}$ above the ground state of the charge-reduced cation radical.

The molecular orbitals of the electronic states corresponding to electron capture in the $\operatorname{Ar}_{3} \mathrm{P}$ group were modeled using the THPP- $\mathrm{CH}_{2} \mathrm{CONH}_{2}$ radical (Figure S4, Supplementary Material). The low-lying excited states show extensive delocalization of electron density by interaction of phosphorus $3 \mathrm{~d}, 4 \mathrm{~s}$, and $4 \mathrm{p}$ orbitals with the $\pi^{*}$ and $\sigma^{*}$ orbitals of the aryl substituents. 


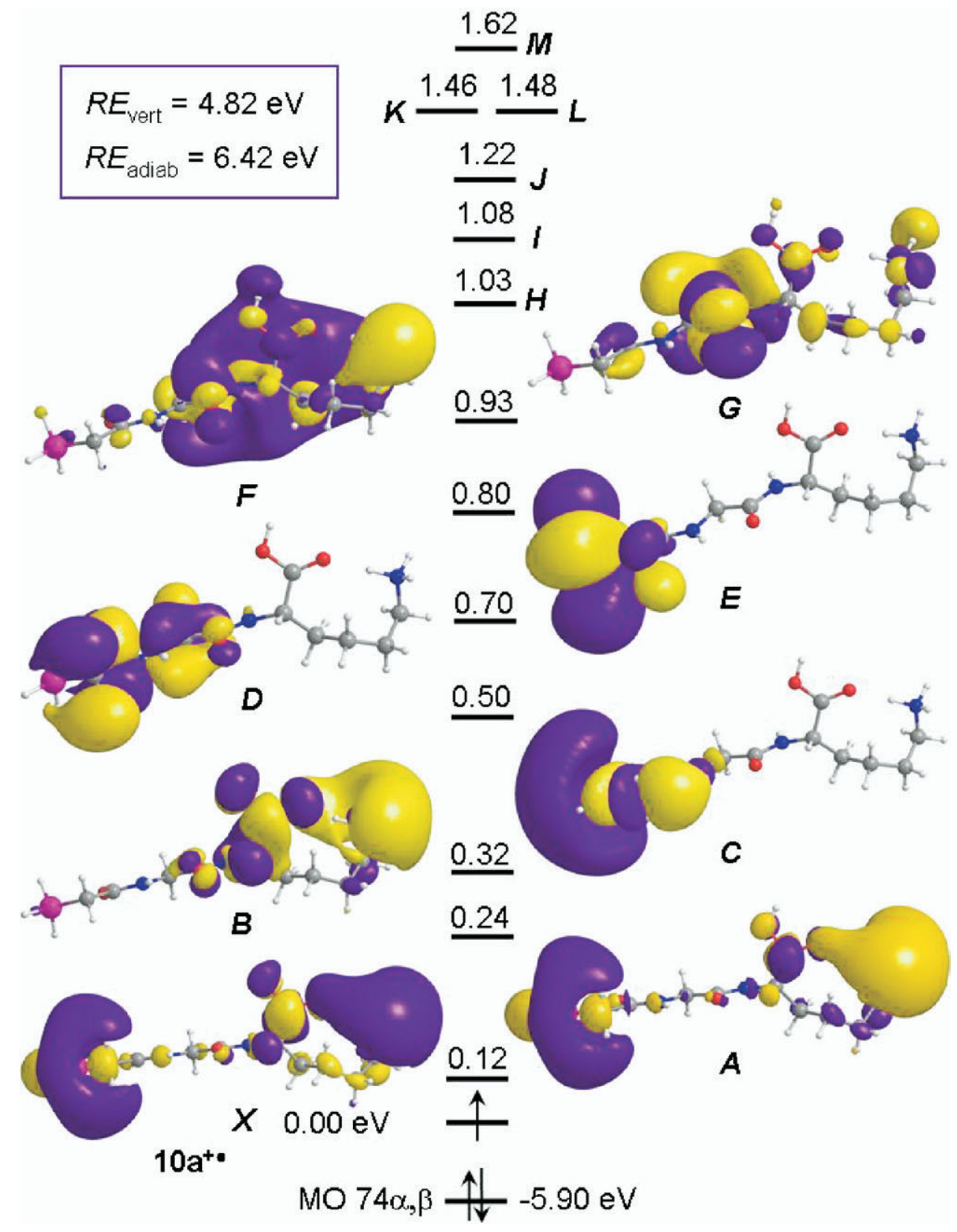

Figure 6. Electronic states and vertical excitation energies in $10 \mathrm{a}^{+\cdot}$ from TD-B3LYP $/ 6-311++\mathrm{G}(2 \mathrm{~d}, \mathrm{p})$ calculations.

Cleavage of the $\mathrm{P}-\mathrm{CH}_{2} \mathrm{CONH}_{2}$ bond in the radical was calculated to be 29 to $32 \mathrm{~kJ} \mathrm{~mol}^{-1}$ exothermic and required a low activation energy, e.g., $E_{\mathrm{TS}}=4 \mathrm{~kJ} \mathrm{~mol}^{-1}$ in $\mathrm{TPP}^{\bullet} \mathrm{CH}_{2} \mathrm{CONH}_{2}$. However, in the ECD experiments the incipient TMPP and ${ }^{\circ} \mathrm{CH}_{2} \mathrm{CONH}-\mathrm{GK}^{+}$fragments do not separate immediately after the $\mathrm{P}-\mathrm{C}_{\alpha}$ bond cleavage, as evidenced by the absence of the ${ }^{\circ} \mathrm{CH}_{2} \mathrm{CONH}$ dipeptide $^{+}$cation-radicals at $m / z 245$ for GK and KG, $m / z 259$ for $\mathrm{AK}$ and KA, and $m / z 273$ for GR. As suggested in Scheme 6, the fragments remain temporarily engaged in an ion-molecule complex to allow proton transfer to occur. Interestingly, the calculated 298 K gas-phase basicity of tris-(2,4,6-trihydroxyphenyl)phosphine $\left(\mathrm{GB}_{298}=1064 \mathrm{~kJ} \mathrm{~mol}^{-1}\right)$, which represents a lower limit for the GB of the more electron-rich TMPP, exceeds the gas-phase basicity of Gly-Lys that was estimated at 934 to $953 \mathrm{~kJ} \mathrm{~mol}^{-1}$ by previous measurements [37], and is also above the gas-phase basicity of arginine $\left(992 \mathrm{~kJ} \mathrm{~mol}^{-1}\right)$ [37]. Thus, proton transfer to $\mathrm{Ar}_{3} \mathrm{P}$ from the ${ }^{\bullet} \mathrm{CH}_{2} \mathrm{CONH}$-peptide ${ }^{+}$fragment is exothermic for both lysine and arginine. We note that the incipient $\mathrm{Ar}_{3} \mathrm{P}$ fragment is spatially remote from the protonated lysine or arginine side chains in the reactants $\mathbf{1}^{+}-\mathbf{5}^{+} \bullet$, as well as in the transition-state for the $\mathrm{P}-\mathrm{C}_{\boldsymbol{c}}$ bond cleavage. The fact that quantitative proton transfer to $\mathrm{Ar}_{3} \mathrm{P}$ occurs, as dictated by the reaction thermochemistry, is evidence that the incipient fragments interact in an ion-molecule complex before separation. 


\section{Doubly Tagged and Arginine Peptide Ions}

We now discuss the electron-induced dissociations of the doubly TMPP-labeled peptide ions $\mathbf{6}^{2+}-\mathbf{9}^{2+}$ and the $(\mathrm{TMPP}-\mathrm{ac}-\mathrm{GR})^{2+}$ ion $5^{2+}$. Ions $\mathbf{6}^{2+}-\mathbf{9}^{2+}$ completely dissociate by fragmentations within the TMPP moieties, but do not undergo backbone $\mathrm{N}-\mathrm{C}_{\alpha}$ bond cleavages. This behavior is different from the dissociations of larger peptides that were charge-tagged with trimethylalkylammonium groups [19] and did undergo regular $\mathrm{N}-\mathrm{C}_{c}$ cleavages. This indicates that the electronic structure of the fixed-charge group and its interactions with the $\pi^{*}$ orbitals of the peptide amide groups are important for the dissociations upon electron capture. The lack of $\mathrm{N}-\mathrm{C}_{\alpha}$ bond dissociations in $\mathbf{6}^{2+}-\mathbf{9}^{2+}$ indicates that electron attachment in the peptide orbitals that could trigger dissociations is inefficient. This may be due to the high density of electronic states within the TMPP groups (Figure S4) that promote C-P bond dissociations while disfavoring electron-transfer to the reactive $\pi^{*}$ amide orbitals.

Ion $5^{2+}$ contains a guanidinium group which is an inefficient hydrogen atom donor in arginine radicals when formed in their ground electronic state [11]. However, the guanidinium group can exothermically transfer a proton to a reduced carboxyl or amide group in an excited electronic state, according to the UW mechanism (see above). It is noteworthy that the ground electronic state of a guanidinium radical with its puckered geometry poorly matches the planar guanidinium cation [11] and disfavors electron attachment in the guanidinium because of an unfavorable FranckCondon overlap. Thus, electron capture in the $\pi^{*}$ carboxyl and amide orbitals can be particularly efficient in arginine containing peptides.

Also noteworthy is the presence of the $\mathrm{m} / \mathrm{z} 638$ peak in the ECD spectrum of $5^{2+}$ which is due to the elimination of a 2,4,6-trimethoxyphenyl group from TMPP. As discussed for $6^{2+}-9^{2+}$, this dissociation is triggered by electron capture in the TMPP group. The fact that it occurs in $5^{2+}$ is consistent with the low vertical recombination energy of the protonated guanidine group $(2.81 \mathrm{eV})$, so that the electronic state manifolds of the guanidinium and TMPP radicals overlap. Furthermore, loss of a neutral guanidine molecule from $5^{2+}(\mathrm{m} / \mathrm{z} 746)$ is negligible (Figure 2), in contrast with ECD of arginine-containing peptides where it represents a major low-energy dissociation pathway [11]. Its absence in ECD of $5^{2+}$ indicates that the electron reaches the electronic states of the guanidine moiety in a negligible small fraction of charge-reduced ions. This may be due to a difference in the density of electronic and vibrational states at the TMPP and guanidinium groups in the incipient cation radical. The TMPP group shows only small changes of geometry upon electron capture (cf. Figure S2). In contrast, the relaxed geometries of the guanidinium ion and radical are different (Scheme 4) causing large Franck-Condon effects in electron attachment [11], which decrease the density of states for electron capture at the guanidinium group. Given the similarity of the recombination energies of TMPP and guanidinium ions, the probability for electron attachment can be largely determined by the local density of states to favor capture at the TMPP group.

\section{Conclusions}

Electron-capture dissociation of charge-tagged GK, KG, $\mathrm{AK}, \mathrm{KA}$, and GR dipeptide dications showed strong dependence on the charge type. Backbone $\mathrm{N}-\mathrm{C}_{\alpha}$ bond cleavages were observed only in the presence of lysine ammonium or arginine guanidinium groups. In the absence of the charged peptide groups the ions dissociated by $\mathrm{P}-\mathrm{C}$ bond cleavages in the triarylphosphonium groups. These results can be interpreted by a combination of a relay-type mechanism operating on the ground electronic-state potential energy surface and the Utah-Washington mechanism involving $\pi^{*}$ amide orbitals in low-lying excited electronic states and accompanied by proton transfer. The relative importance of these two mechanisms cannot be determined from the current experiments. The fact that the $\mathrm{N}-\mathrm{C}_{\alpha}$ bond cleavages occur in the presence of arginine, which is an inefficient hydrogen atom donor, indicates that the UW mechanism may predominate.

\section{Acknowledgments}

FT thanks the National Science Foundation for support through grants CHE-0349595 for experiments and CHE-0342956 for computations, and the Laboratory of Reaction Mechanisms at Ecole Polytechnique, Palaiseau, France, for a visiting fellowship in September 2006. JCR thanks Emilie Biteau for some ECD experiments and G. van der Rest for fruitful discussions.

\section{References}

1. Tureček, F. Transient Intermediates of Chemical Reactions by Neutralization-Reionization Mass Spectrometry. Top. Curr. Chem. 2003, 225, 77-129.

2. Zubarev, R. A.; Kelleher, N. L.; McLafferty, F. W. Electron Capture Dissociation of Multiply Charged Protein Cations. A Nonergodic Process. J. Am. Chem. Soc. 1998, 120, 3265-3266.

3. Zubarev, R. A.; Horn, D. M.; Fridriksson, E. K.; Kelleher, N. L.; Kruger N. A.; Lewis, M. A.; Carpenter, B. K.; McLafferty, F. W. Electron Capture Dissociation for Structural Characterization of Multiply Charged Protein Cations. Anal. Chem. 2000, 72, 563-573.

4. Rowe, B. R.; Mitchell, J. B.; Canosa, A. Dissociative Recombination. Theory, Experiment, and Applications; Plenum Press: New York, 1993; pp. 1-11.

5. Cooper, H. J.; Hakansson, K.; Marshall, A. G. The role of electron capture dissociation in biomolecular analysis. Mass Spectrom. Rev. 2005, 24, 201-222.

6. (a) Zubarev, R. A.; Horn, D. M.; Fridriksson, E. K.; Kelleher, N. L.; Kruger, N. A.; Lewis, M. A.; Carpenter, B. K.; McLafferty, F. W. Anal. Chem. 2000, 72, 563-573. (b) Leymarie, N.; Costello, C. E.; O'Connor, P. B. Electron. Capture Dissociation Initiates a Free Radical Reaction Cascade. J. Am. Chem. Soc. 2003, 125, 8949-8958. (c) Fung, Y. M. E.; Chan, T.-W. D. Experimental and Theoretical Investigations of the Loss of Amino Acid Side Chains in Electron Capture Dissociation of Model Peptides. J. Am. Soc. Mass Spectrom. 2005, 16, 1523-1535. (d) O'Connor, P. B.; Lin, C.; Cournoyer, J. J.; Pittman, J. L.; Belyayev, M.; Budnik, B. A. Long-Lived. Electron Capture Dissociation Product Ions Experience Radical Migration via Hydrogen Abstraction. J. Am. Soc. Mass Spectrom. 2006, 17, 576-585. (e) Lin, C.; Cournoyer, J. J.; O'Connor, P. B. Use of a Double Resonance Electron Capture Dissociation Experiment to Probe Fragment Intermediate Lifetimes. J. Am. Soc. Mass Spectrom. 2006, 17, 1605-1615.

7. (a) Konishi, H.; Yokotake, Y.; Ishibashi, T. Theoretical Study on the Electron Capture Dissociation Correlated with Proton Transfer Pro- 
cesses. J. Mass Spectrom. Soc. Jpn. 2002, 50, 222-225. (b) Bakken, V.; Helgaker, T.; Uggerud, E. Models of Fragmentations Induced by Electron Attachment to Protonated Peptides. Eur. J. Mass Spectrom. 2004, 10, 625-638.

8. Tureček, F.; Syrstad, E. A. Mechanism and Energetics of Intramolecular Hydrogen Transfer Atom Transfer in Amide and Peptide Radicals and Cation-Radicals I. Am. Chem. Soc. 2003, 125, 3353-3369.

9. Tureček, F. N-C $\mathrm{C}_{\alpha}$ Bond Dissociation Energies and Kinetics in Amide and Peptide Radicals. Is the Dissociation a Non-Ergodic Process? J. Am. Chem. Soc. 2003, 125, 5954-5963.

10. Tureček, F.; Syrstad, E. A.; Seymour, J. L.; Chen, X.; Yao, C. Peptide Cation-Radicals. A Computational Study of the Competition between Peptide $\mathrm{N}-\mathrm{C}_{u}$ Bond Cleavage and Loss of the Side Chain in the [GlyPhe- $\left.\mathrm{NH}_{2}{ }^{2}+2 \mathrm{H}\right]^{+\cdot}$ Cation Radical. J. Mass Spectrom. 2003, 38, 1093-1104

11. Chen. X.; Tureček, F. The Arginine Anomaly. Arginine Radicals are Poor Hydrogen Atom Donors in Electron Transfer Induced Dissociations. J. Am. Chem. Soc. 2006, 128, 12520-12530.

12. Yao, C.; Fung, Y. M. E.; Tureček, F. Histidine Radicals. Proceedings of the UPPCON IV Conference, Hong Kong, December, 2006.

13. Yao, C.; Syrstad, E. A.; Tureček, F. Electron Transfer to Protonated B-Alanine N-Methylamide in the Gas Phase: An Experimental and Computational Study of Dissociation Energetics and Mechanisms. J. Phys. Chem. A 2007, 111, 4167-4180.

14. Syrstad, E. A.; Tureček, F. Toward a General Mechanism of Electron Capture Dissociation. J. Am. Soc. Mass Spectrom. 2005, 16, 208-224.

15. (a) Sobczyk, M.; Anusiewicz, I.; Berdys-Kochanska, J.; Sawicka, A.; Skurski, P.; Simons, J. Coulomb-Assisted Dissociative Electron Attachment: Application to a Model Peptide. J. Phys. Chem. A 2005, 109, 250-258. (b) Anusiewicz, I.; Berdys-Kochanska, J.; Skurski, P.; Simons, J. Simulating Electron Transfer Attachment to a Positively Charged Model Peptide. J. Phys. Chem. A 2006, 110, 1261-1266. (c) Skurski, P.; Sobczyk M.; Jakowski, J.; Simons, J. Possible Mechanisms for Protecting N-C bonds in helical peptides from electron capture (or transfer) dissociation. Int. J. Mass Spectrom. 2007, 265, 197-212.

16. Huang, Z.-H.; Wu, J.; Roth, K. D. W.; Yang, Y.; Gage, D. A.; Watson, J. T. A Picomole-Scale Method for Charge Derivatization of Peptides for Sequence Analysis by Mass Spectrometry. Anal. Chem. 1997, 69, 137-144.

17. Sadagopan, N.; Watson, J. T. Investigation of the Tris(Trimethoxyphenyl) Phosphonium Acetyl Charge Derivatives of Peptides by Electrospray Ionization Mass Spectrometry and Tandem Mass Spectrometry. J. Am. Soc. Mass Spectrom. 1999, 11, 107-119.

18. Chamot-Rooke, J.; van der Rest, G.; Dalleu, A.; Bay, A.; Lemoine, J. The Combination of Electron Capture Dissociation and Fixed Charge Derivatization Increases Sequence Coverage for O-Glycosylated and OPhosphorylated Peptides. J. Am. Soc. Mass Spectrom. 2007, 18, 1405-1413.

19. Gunawardena, H. P.; Gorenstein, L.; Erickson, D. E.; Xia, Y.; McLuckey, S. A. Electron Transfer Dissociation of Multiply Protonated and Fixed Charge Disulfide Linked Polypeptides. Int. J. Mass Spectrom. 2007, 265, $130-138$.

20. Frisch, M. I.; Trucks, G. W.; Schlegel, H. B.; Scuseria, G. E.; Robb, M. A.; Cheeseman, J. R.; Montgomery, J. A., Jr.; Vreven, T.; Kudin, K. N.; Burant, J. C.; Millam, J. M.; Iyengar, S. S.; Tomasi, J.; Barone, V.; Mennucci, B.; Cossi, M.; Scalmani, G.; Rega, N.; Petersson, G. A.; Nakatsuji, H.; Hada, M.; Ehara, M.; Toyota, K.; Fukuda, R.; Hasegawa, J.; Ishida, M.; Nakajima, T.; Honda, Y.; Kitao, O.; Nakai, H.; Klene, M.; Li, X.; Knox, J. E.; Hratchian, H. P.; Cross, J. B.; Adamo, C.; Jaramillo, J.; Gomperts, R.; Stratmann, R. E.; Yazyev, O.; Austn, A. J.; Cammi, R.; Pomelli, C.; Ochterski, J.,W.; Ayala, P. Y.; Morokuma, K.; Voth, G. A.; Salvador, P.; Dannenberg, J. J.; Zakrzewski, V. G.; Dapprich, S.; Daniels, A. D.; Strain, M. C.; Farkas, O.; Malick, D. K.; Rabuck, A. D.; Raghavachari, K.; Foresman, J. B.; Ortiz, J. V.; Cui, Q.; Baboul, A. G.; Clifford, S.; Cioslowski, J.; Stefanov, B. B.; Liu, G.; Liashenko, A.; Piskorz, P.; Komaromi, I.; Martin, R. L.; Fox, D. J.; Keith, T.; Al-Laham, M. A.; Peng, C. Y.; Nanayakkara, A.; Challacombe, M.; Gill, P. M. W.; Johnson, B.; Chen, W.; Wong, M. W.; Gonzalez, C.; Pople, J. A. Gaussian 03, Revision B-05; Gaussian, Inc.: Pittsburgh PA, 2003.

21. (a) Becke, A. D. A New Mixing of Hartree-Fock and Local DensityFunctional Theories. J. Chem. Phys. 1993, 98, 1372-1377. (b) Becke, A. D. Density Functional Thermochemistry. III. The Role of Exact Exchange. J. Chem. Phys. 1993, 98, 5648-5652.

22. Yao, C.; Tureček, F. Hypervalent Ammonium Radicals. Competitive $\mathrm{N}-\mathrm{C}$ and N-H Bond Dissociations in Methylammonium and Ethylammonium. Phys. Chem., Chem. Phys. 2005, 7, 912-920.

23. Rauhut, G.; Pulay, P. Transferable Scaling Factors for Density Functional Derived Vibrational Force Fields. J. Phys. Chem. 1995, 99, 30933100.

24. Møller, C.; Plesset, M. S. A Note on an Approximation Treatment for Many-Electron Systems. Phys. Rev. 1934, 46, 618-622.
25. (a) Schlegel, H. B. Potential Energy Curves Using Unrestricted MollerPlesset Perturbation Theory with Spin Annihilation. J. Chem. Phys. 1986 84, 4530-4534. (b) Mayer, I. Spin-Projected UHF Method. IV. Comparison of Potential Curves Given by Different One-Electron Methods. Adv. Quantum. Chem. 1980, 12, 189-262.

26. (a) Tureček, F. Proton Affinity of Dimethyl Sulfoxide and Relative Stabilities of $\mathrm{C}_{2} \mathrm{H}_{6} \mathrm{OS}$ Molecules and $\mathrm{C}_{2} \mathrm{H}_{7} \mathrm{OS}^{+}$Ions. A Comparative G2(MP2) ab Initio and Density Functional Theory Study. J. Phys. Chem. A 1998, 102, 4703-4713. (b) Tureček, F.; Wolken, J. K. Dissociation Energies and Kinetics of Aminopyrimidinium Radicals by ab Initio and Density Functional Theory. I. Phys. Chem. A 1999, 103, 1905-1912. (c) Tureček, F.; Polašek, M.; Frank, A. J.; Sadilek, M. Transient Hydrogen Atom Adducts to Disulfides Formation and Energetics. J. Am. Chem. Soc. 2000, 122, 2361-2370. (d) Polašek, M.; Tureček, F. Hydrogen Atom Adducts to Nitrobenzene Formation of the Phenylnitronic Radical in the Gas Phase and Energetics of Wheland Intermediates. J. Am Chem. Soc. 2000, 122, 9511-9524. (e) Rablen, P. R. Is the Acetate Anion Stabilized by Resonance or Electrostatics? A Systematic Structural Comparison. J. Am. Chem. Soc. 2000, 122, 357-368. (f) Rablen, P. R. Computational Analysis of the Solvent Effect on the Barrier to Rotation about the Conjugated C-N Bond in Methyl N,N-Dimethylcarbamate. J. Org. Chem. 2000, 65, 7930-7937. (g) Rablen, P. R.; Bentrup, K. H. Are the Enolates of Amides and Esters Stabilized by Electrostatics? J. Am. Chem Soc. 2003, 125, 2142-2147. (h) Hirama, M.; Tokosumi, T.; Ishida, T.; Aihara, J. Possible Molecular Hydrogen Formation Mediated by the Inner and Outer Carbon Atoms of Typical PAH cations. Chem. Phys. 2004, 305, 307-316

27. Čižek, J.; Paldus, J.; Šroubkova, L. Cluster Expansion Analysis for Delocalized Systems. Int. J. Quantum. Chem. 1969, 3, 149-167.

28. Purvis, G. D., III; Bartlett, R. J. A Full Coupled-Cluster Singles and Doubles model: The Inclusion of Disconnected Triples. J. Chem. Phys. 1982, 76, 1910-1918.

29. (a) Dunning, T. H., Jr. Gaussian Basis Sets for Use in Correlated Molecular Calculations. I. The Atoms Boron through Neon and Hydrogen. J. Chem. Phys. 1989, 90, 1007-1023. (b) Woon, D. E.; Dunning, T. H., Jr. Gaussian Basis Sets for Use in Correlated Molecular Calculations. III. The Atoms Aluminum through Argon. J. Chem. Phys. 1993, 98, 1358 1371.

30. Stratmann, R. E.; Scuseria, G. E.; Frisch, M. J. An Efficient Implementation of Time-Dependent Density Functional Theory for the Calculation of Excitation Energies of Large Molecules. J. Chem. Phys. 1998, 109, $8218-8224$.

31. Reed, A. E.; Weinstock, R. B.; Weinhold, F. Natural Population Analysis. J. Chem. Phys. 1985, 83, 735-746.

32. (a) Roepstorff, P.; Fohlman, J. Proposal for a Common Nomenclature for Sequence Ions in Mass Spectra of Peptides. Biomed. Mass Spectrom. 1984, 11, 601. (b) Johnson, R. S.; Martin, S. A.; Biemann, K. Collision-Induced Fragmentation of $(\mathrm{M}+\mathrm{H})^{+}$ions of peptides. Side Chain Specific Sequence Ions. Int. J. Mass Spectrom. Ion Processes 1988, 86, 137-154.

33. McLafferty, F. W.; Tureček, F. Interpretation of Mass Spectra, 4th ed.; University Science Books: Mill Valley, CA, 1993; pp. 19-26.

34. (a) Clareboudt, J.; Baten, W.; Geise, H.; Claeys, M. Structural Characterization of Mono- and Biphosphonium Salts by Fast Atom Bombardment Mass Spectrometry and Tandem Mass Spectrometry. Org. Mass Spectrom. 1993, 28, 71-82. (b) NIST Standard Reference Database Number 69, June 2005 Release, http://webbook.nist.gov/chemistry.

35. (a) Gustafson, S. M.; Cramer, C. J. Ab Initio Conformational and Stereopermutational Analyses of Phosphoranyl Radicals HP(OR)3 and $\mathrm{P}(\mathrm{OR}) 4[\mathrm{R}=\mathrm{H}$ or CH3]. J. Phys. Chem. 1995, 99, 2267-2277. (b) Tureček, F.; Gu, M.; Hop. C. E. C. A. Franck-Condon Dominated Chemistry Formation and Dissociations of Tetrahydroxyphosphoranyl Radicals Following Femtosecond Reduction of Their Cations in the Gas Phase. I. Phys. Chem. 1995, 99, 2278-2291. (c) Cramer, C. J. The Fluorophosphoranyl Series: Theoretical Insights into Relative Stabilities and Localization of Spin. J. Am. Chem. Soc. 1991, 113, 2439-2447. (d) Cramer, C. J. Computational Studies of Open-Shell Phosphorus Oxyacids. Pt. 3. Theoretical Rotation, Pseudorotation, and Pseudoinversion Barriers for the Hydroxyphosphoranyl Radical. J. Am. Chem. Soc. 1990, 112, 79657972 .

36. (a) Siegbahn, P. E. M.; Blomberg, M. R. A.; Crabtree, R. H. Hydrogen Transfer in the Presence of Amino Acid Radicals. Theor. Chem. Acc. 1997, 97, 289-300. (b) Siegbahn, P. E. M.; Eriksson, L.; Himo, F.; Pavlov, M. Hydrogen Atom Transfer in Ribonucleotide Reductase (RNR). J. Phys. Chem. B 1998, 102, 10622-10629. (c) Cujier, R. L.; Nocera, D. G. Proton-Coupled Electron Transfer. Annu. Rev. Phys. Chem. 1998, 49, 337-369.

37. Harrison, A. G. The Gas-Phase Basicities and Proton Affinities of Amino Acids and Peptides. Mass Spectrom. Rev. 1997, 16, 201-217. 